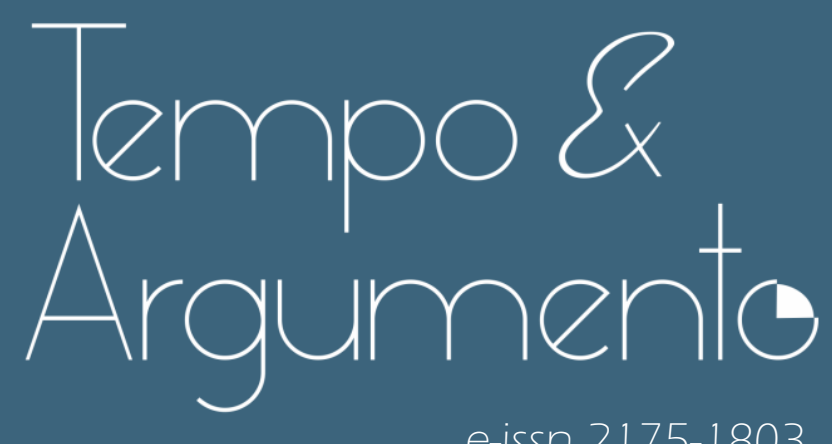

e-issn 2175-1803

\title{
Trazos interrumpidos: humoristas mujeres en la prensa de humor (Argentina, 1974-1984)
}

- Mara Burkart

Doctora en Ciencias Sociales por la Universidad de Buenos Aíres (UBA).

Investigadora adjunta del Consejo Nacional de Investigaciones en

Ciencia y Técnica (CONICET).

Docente de Historia Social Latinoamericana en la Carrera de Sociología de

la Facultad de Ciencias Sociales de la Universidad de Buenos Aíres (UBA)

Buenos Aires - ARGENTINA

uba.academia.edu/MaraBurkart/

burkartmara@gmail.com

(i) orcid.org/0000-0003-3197-7458

Para citar este articulo:

BURKART, Mara. Trazos interrumpidos: humoristas mujeres en la prensa de humor (Argentina, 1974-1984). Tempo e Argumento, Florianópolis, v. 12, n. 31, e0 105, set./dez. 2020.

doi http://dx.doi.org/10.5965/2175180312312020e0105

Recebido: 13/03/2020

Aprovado: 26/05/2020 


\title{
Trazos interrumpidos: humoristas mujeres en la prensa de humor (Argentina, 1974-1984)
}

\begin{abstract}
Resumen
En la Argentina, el humor gráfico fue una profesión mayoritariamente masculina hasta los años ochenta del siglo XX cuando varias mujeres - Maitena, Patricia Breccia, María del Carmen Alcobre, Petisuí, Ana von Reuber- comenzaron a publicar sus tiras en las revistas de Ediciones de la Urraca. Antes de esta irrupción, entre 1974 y 1984, Nelly Hoijman, Patricia Breccia, Lucía Capozzo y Marta Vicente produjeron tiras humorísticas que se publicaron en esas revistas de humor gráfico donde primaban las firmas de varones. Por diversos motivos y salvo Breccia, el resto lo hizo por un período breve de tiempo para luego, dedicarse a otras profesiones. Inspirado teórica y metodológicamente en los aportes de la historia social dirigidos a problematizar la invisibilidad de las mujeres en la vida social, en las preguntas y los estudios que desde hace décadas vienen realizando historiadoras del arte feministas como Linda Nochlin y Griselda Pollock en relación al lugar de las mujeres en las "bellas artes" y Whitney Chadwick e Isabelle de Courtivron sobre la relación entre creatividad y relaciones íntimas, en este trabajo analizamos el paso de estas mujeres por el humor gráfico. Me interesa identificar las condiciones sociales de su producción así como también analizar los temas y las representaciones plasmadas en sus respectivas obras a la luz de los demás contenidos de las revistas donde publicaron. El objetivo último es generar un aporte a una nueva historia del humor gráfico que dé cuenta del lugar de las mujeres en la producción humorística y en los medios de comunicación masiva.
\end{abstract}

Palabras clave: Mujer Artista. Humor. Prensa Periódica. Argentina.

\section{Interrupted lines: women humorists in the humor press (Argentina, 1974-1984)}

\begin{abstract}
In Argentina, graphic humor was a mostly male profession until the eighties of the twentieth century when several women - Maitena, Patricia Breccia, Maria del Carmen Alcobre, Petisuí, Ana von Reuber- began publishing their strips in the magazines of Ediciones de la Urraca. Before this irruption, between 1974 and 1984, Nelly Hoijman, Patricia Breccia, Lucía Capozzo and Marta Vicente produced and published humorous strips in those graphic humor magazines where male firms prevailed. For various reasons and except Breccia, the rest did it for a short period and then dedicated to other professions. Theoretically and methodologically inspired by the contributions of social history aimed at problematizing the invisibility of women in social life. Moreover, in the questions and studies that feminists art historian such as Linda Nochlin and Griselda Pollock have been carrying out for decades in relation to the place of women in the "fine arts", and Whitney Chadwick and Isabelle de Courtivron on the relationship between creativity and intimate relationships, in this work we analyze the passage of these women through humor graphic. This article focus in identifying the social conditions of their production as well as analyzing the themes and representations embodied in their respective works in light of the other contents of the magazines where they published. Its aim is to generate a contribution to a new history of graphic humor that accounts for the place of women in humorous production and in the mass media.
\end{abstract}

Keywords: Woman Artist. Humor. Periodical Press. Argentine.

\footnotetext{
Este trabajo se inserta en el proyecto PICT 2020-2023 "Cultura masiva y género: el trabajo de las mujeres en el campo del humor gráfico y la historieta durante la segunda mitad del siglo XX" y no hubiera sido posible sin la ayuda y la buena predisposición de Mariela Acevedo, Lorenzo Amengual, Luchía Arturi, Patricia Breccia, Lucía Capozzo, Judith Gociol, Nelly Hoijman, Domingo Mandrafina, Verónica Milenaar, Mabel Thwaites Rey y Marta Vicente. Agradezco también a lxs evaluadorxs, sus comentarios han enriquecido el trabajo; y advierto que los errores me corresponden íntegramente a mí.
} 
En la Argentina, el humor gráfico fue una profesión mayoritariamente de varones hasta los años ochenta del siglo XX cuando varias mujeres - Maitena (Maitena Burundarena), Patricia Breccia, María del Carmen Alcobre, Petisuí (María Alicia Guzmán), Ana von Reuber, entre otras- comenzaron a publicar sus tiras con regularidad en las revistas de Ediciones de la Urraca, en especial, en Fierro y en Sexhumor (ACEVEDO, 2017). Antes de esta irrupción, Nelly Hoijman y Patricia Breccia publicaron en las revistas Mengano y Siete Días; y Lucía Capozzo (que firmaba como Lucy de Saccomanno) y Marta Vicente lo hicieron en HUM® entre 1979 y 1984, pero de forma breve. Patricia Breccia también publicó en HUM® y lo hizo desde sus inicios hasta su cierre, con algunas intermitencias. Entre 19791984 la humorista francesa Claire Bretécher tuvo continuidad y reconocimiento en $H U M \otimes$ y SuperHUM®. Bretechér contó con la admiración de los humoristas argentinos varones y la circulación de su obra traducida al castellano buscó alentar implícitamente la participación de mujeres en el humor gráfico (BURKART, 2018). En este artículo me propongo analizar las experiencias autorales y editoriales de Hoijman, Breccia, Capozzo y Vicente en la producción de humor gráfico. Si bien fueron breves en el tiempo, fueron eslabones relevantes a la hora de problematizar el lugar de las mujeres en la vida social en general y en las artes gráficas y en el humor gráfico, en particular. Para ello, identificaré las posibilidades y obstáculos que tuvieron las autoras, así como también analizaré los temas y las representaciones plasmadas en sus obras a la luz de los trabajos realizados por otros humoristas varones contemporáneos.

En los últimos años, las movilizaciones de mujeres y la revitalización de los feminismos en Argentina y otras partes del mundo legitimaron de forma novedosa los estudios críticos feministas e incentivaron los estudios de género ${ }^{2}$ y el auge de las teorías críticas feministas (GIUNTA, 2018). Este trabajo no escapa a ese nuevo contexto aunque retoma preguntas y marcos teóricos ya clásicos pero dirigidos a echar luz hacia una profesión soslayada: la de humorista

\footnotetext{
2 Nos referimos a \#niunamenos, un gran movimiento de mujeres que salió a manifestarse contra la violencia machista en Argentina en 2015 y que se replicó en otros países. Desde entonces, manifestaciones callejeras y huelgas de mujeres se han sucedido en el país y en otros lugares, así como campañas contra abusos sexuales como \#metoo que surgió cuando se hicieron públicas las acusaciones contra el productor de cine estadounidense Harvey Weinstein en los Estados Unidos en 2017.
} 
gráfico/a. De este modo, está inspirado teórica y metodológicamente en los aportes de la historia social dirigidos a problematizar la invisibilidad de las mujeres en la vida social en la línea propuesta por Dora Barrancos (2010) y en los estudios que desde hace décadas vienen realizando historiadoras del arte feministas sobre el lugar de las mujeres en el arte y sobre la relación entre creatividad y relaciones íntimas.

Uno de los trabajos pioneros que revolucionó la historia del arte fue "¿Por qué no han existido grandes artistas mujeres?” de Linda Nochlin (2001). La explicación de Nochlin era que las artistas no habían tenido acceso a la misma educación artística ni a las mismas instituciones que los varones pero, como recuerda Griselda Pollock (2013), Nochlin ya advertía que el criterio de grandeza en las Artes estaba definido por la masculinidad: "en el campo de la historia del arte, el punto de vista del varón blanco occidental, [ha sido] inconscientemente aceptado como el punto de vista" (2001, p. 17). Pollock (2013, 2001) articuló marxismo y feminismo y puso en jaque al canon occidental de las artes plásticas al sostener que la construcción misma del artista -que lo concibe como héroe de la modernidad- era sexista, no existe una figura semejante en femenino. Como reseña Laura Malosetti Costa (2013, p. 13), para Pollock "Las mujeres tuvieron otros lugares, otras miradas y una posición de poder radicalmente diferente, subalterna, soslayada sistemáticamente".

Esta caracterización sexista de las llamadas bellas artes se puede extender al humor gráfico, como se verá en el primer apartado, y por eso nos proponemos revisar una parte de su historia en la Argentina para identificar a las mujeres que produjeron la risa y los desafíos que debieron enfrentar. En este campo, Frances Gray (1994) analizó las relaciones entre las mujeres y la producción de risa, y su conclusión fue que en la exclusión o invisibilización de las mujeres humoristas opera social y políticamente el mito de que las mujeres no tienen sentido del humor. Mito que debería desvanecerse si reconocemos junto a los principales teóricos del humor y la comicidad que la experiencia de lo cómico se encuentra en todas las culturas y que esta universalidad se debe a que es una parte central y necesaria de la vida social y que, sin la posibilidad de la risa, la vida social "seria" no podría sostenerse como argumenta Peter Berger (1999). Entonces si es así, 
¿cómo es posible afirmar que las mujeres no tienen sentido del humor? ¿Acaso no son también los sujetos de esas culturas? Escapa a los límites de este artículo confirmar o rechazar esta teoría en todas sus dimensiones, pero sí nos interesa indagar las construcciones simbólicas acerca de la relación de las mujeres con el humor, y cuestionar los mitos, la ideología y el sentido común que "devalúa a las mujeres dándoles a ellas, a sus roles, sus labores, sus productos y su entorno social, menos prestigio y/o poder que el que se le da a los de los hombres" (FACIO; FRIES, 2005).

Asimismo, ¿podemos hablar de mujeres humoristas en tiempos en los que está siendo cuestionada la división entre hombres y mujeres, y cuando sabemos que la sexualidad es una orientación cultural e identitaria y no una determinación biológica? Siguiendo a Andrea Giunta (2018), tomo la noción de "humoristas mujeres" para referirme a quienes la sociedad y sus instituciones clasifican como mujeres. Es en este sentido que la historia, o mejor dicho, las historias de las humoristas gráficas argentinas y, más en general, de las humoristas aún está pendiente de escribirse. En la Argentina, la presencia de mujeres en el mundo de la historieta, género hermano del humor gráfico, pero con propiedades, publicaciones e instituciones específicas ha sido abordada recientemente por Mariela Acevedo (2019) quien analiza la emergencia de "lo femenino" en las distintas etapas que tuvo la revista Fierro a partir de un enfoque feminista. En las bellas artes o artes plásticas, también hay trabajos muy bien documentados y originales que han echado luz sobre la presencia y la autoría femeninas como los Libros de María Laura Rosa (2014), Georgina Gluzman (2016) y, el más reciente, de Andrea Giunta, que incluye al cine en esas $\operatorname{artes}^{3}$ (2018). En cuanto a la literatura, Francine Masiello (1994, 2007), analizó el periodismo femenino y a las mujeres en la cultura literaria argentina durante el siglo XIX.

Sin embargo, muy poco ha sucedido en cuanto a los estudios sobre humor en la Argentina. A mediados de los años ochenta, el humorista Siulnas, en su monumental obra sobre la historia del humor gráfico y escrito en la Argentina,

\footnotetext{
${ }^{3}$ Hemos mencionado apenas los libros editados. No desconocemos que hay artículos, ponencias, tesis de posgrado de diferentes autores que estudian a mujeres artistas desde distintas perspectivas, incluyendo trabajos pioneros de Andrea Giunta, como ella misma reseña en su libro, véase: GIUNTA, 2018, p. 55-65.
} 
identificó a algunas mujeres, entre ellas a Nelly Hoijman (VAZQUEZ LUCIO, 1986). Paulina Juszko (2000) tiene un trabajo pionero, El humor de las argentinas. El libro es una antología que constituye el punto de partida para cualquier estudio sobre mujeres humoristas, sin embargo, no logra responder convincentemente al interrogante con el cual se presenta: ¿por qué hay tan pocas humoristas mujeres? En cambio, sobresale por señero el estudio de Cintia Crescêncio Lima (2016) sobre el humor gráfico feminista producido y publicado en Argentina, Brasil, Bolivia y Uruguay entre 1975 y 1988. En el caso de la Argentina, Crescêncio Lima se enfoca en Persona, el periódico del Movimiento de Liberación Femenina que se editó de forma interrumpida entre 1974-1976 y 1980-1986. También Maria Conceição Pires (2020, en prensa) analiza el caso de Persona durante la transición democrática (1984-1986) en comparación con el periódico también feminista brasileño Nós mulheres. A diferencia de estos dos últimos trabajos, en este artículo se analiza la producción humorística de mujeres que no se definían a sí mismas como feministas y que publicaron en revistas de humor gráfico o de interés general orientadas al mercado.

A continuación, presento en el primer apartado un rápido recorrido del lugar de las mujeres en el humor gráfico durante el siglo XX en la Argentina, en el cual se confirma la invisibilización de su presencia o directamente, su ausencia. Luego, analizo el brevísimo paso de Nelly Hoijman por la revista Mengano en 1974; le sigue el caso de la tira "Rita y los oficios" de Patricia Breccia y Lucía Capozzo en la revista $H U M \Theta$ en 1979; y las tiras de Marta Vicente, también en $H U M \Theta$, pero entre 1981 y 1982; y, por último, a modo de cierre, presento unas reflexiones finales.

Ausencias, invisibilizaciones y división sexual del trabajo: las mujeres dedicadas al humor gráfico en la Argentina

La Argentina tiene una extensa y rica historia de humor gráfico, con notables dibujantes y destacadas publicaciones que han perdurado en el tiempo y han fomentado distintos tipos de risa o de comicidad: desde la sátira política al humor erótico pasando por el humor costumbrista, negro, e infantil. También tiene su "salón de la fama" o podio de maestros que honra a los profesionales 
que han obtenido el reconocimiento de sus colegas y del público. Dante Quinterno, Flax, Oski, Guillermo Divito, Quino, Landrú, Sábat, Andrés Cascioli, Caloi, Fontanarrosa son tan solo algunos nombres que se destacaron durante el siglo XX. Muchos más podríamos agregar a esa lista y no cambiaría el hecho de que fue recién en los años noventa que una mujer - nos referimos a Maitenaaccedió por primera vez a ese grupo selecto.

En otras palabras, narrada a partir de los grandes nombres, la historia del humor gráfico argentino fue a lo largo de sus más de doscientos años una cuestión de hombres. Estos eran los únicos que con el plumín hacían reír. Supuestamente ajenas al proceso de elaboración de la risa, las mujeres se limitaban a ser sus personajes, musas inspiradoras de sus humoradas y/o las lectoras/consumidoras de sus producciones humorísticas. Incluso algunos humoristas devenidos editores llamaron a sus revistas con nombre de mujeres Tía Vicenta, Hortensia, María Bizca, por mencionar algunas-, otros crearon protagonistas mujeres para sus tiras - "Mafalda" de Quino es quizá el ejemplo más emblemático pero no el único-, o se arrogaron el derecho a hablar en su nombre y representarlas visualmente siendo célebres en el humor costumbrista "las chicas" de Guillermo Divito, Horacio Altuna o Alfredo Grondona White. Esta división de roles naturalizó la mirada masculina sobre el mundo femenino en el humor gráfico.

Sin embargo, cuando uno observa en detalle la conformación de los equipos de redacción y las listas de colaboradores de las revistas de humor gráfico no hay una total ausencia de mujeres aunque sí estas son muy pocas, lo cual revela la división sexual del trabajo (KERGOAT, 2009). En 1988, Silvia Itkin (1988) hizo la primera revisión de la historia del humor gráfico argentino, atendiendo tanto a la representación de las mujeres en el humor gráfico como a las mujeres humoristas; e hizo un llamado a producir un humor sin sexismo. Dos años más tarde, Paulina Juszko (2000) elaboró un listado con las mujeres humoristas que se habían animado a incursionar en la profesión y a trabajar en redacciones dominadas por hombres, en las cuales la participación de mujeres quedaba limitada a ser secretarias o correctoras de textos. En el listado sobresalía el caso de Tía Vicenta. La revista creada por Landrú en 1957 contó con 
varias mujeres entre sus colaboradores: Blanca Cotta (Cerebela), Martha Larumbe (Fiorella), María T. Mayochi (Moralista), Cecilia Palacio - hija del célebre Lino Palacio (Flax) y hermana de Jorge Palacio (Faruk) -, Beatriz Schaefer Peña, Elba Loizaga (Elva Kan), Ercilia Gómez y María Rosa Senet. Tía Vicenta, fue clausurada en 1966 por el general Onganía y ninguna de estas mujeres es recordada por su producción humorística, ni hay estudios sobre sus obras4.

A comienzos de los años setenta, la transición democrática generó un clima de apertura política y cultural durante el cual se produjo una renovación generacional del humor gráfico: nuevos autores, nuevas publicaciones y la revitalización de tipos de humor hasta entonces replegados irrumpieron con fuerza y se consagraron en los años siguientes (BURKART, 2017). La punta de lanza de la renovación del humor gráfico fueron la revista cordobesa Hortensia (1971-1989), la porteña Satiricón (1972-1974, 1975-1976) y la página de humor gráfico del diario Clarín ${ }^{5}$. El matutino de la familia Noble se llenó de excelentes dibujantes, todos hombres: Sábat, Caloi, Crist, Fontanarrosa y Bróccoli se sumaron a Landrú, lan y Dobal. No fue distinto lo que sucedió con Hortensia y Satiricón. Ninguna de estas publicaciones incluyó a mujeres humoristas gráficas como lo había hecho su antecesora, Tía Vicenta; y esa ausencia pasó desapercibida.

Hortensia, la revista de Alberto Cognigni, incorporó en 1972 a la periodista Ana Irene Blythman conocida como Pequi, su seudónimo, y, en los años ochenta,

\footnotetext{
Esperamos avanzar en ese sentido en un próximo artículo. Un trabajo minucioso sobre los humoristas de Tía Vicenta lo llevó a cabo GANDOLFO, Amadeo. La oposición dibujada: política, oficios y gráfica de los caricaturistas políticos argentinos (1955-1976). Tesis (Doctorado en Ciencias Sociales) - Facultad de Ciencias Sociales, Universidad de Buenos Aires, Buenos Aires, 2014

Sobre la revista Hortensia, véase BURKART, 2017, p. 36-41 y PEREIRA, Priscila. Hortensia, da aventura ao mito cultura humorística e discurso identitário na Córdoba dos anos 1970-1980. 2017. Tesis (Doctorado en Historia) - Instituto de Filosofia e Ciências Humanas, Universidade Estadual de Campinas, Campinas, 2017. Sobre Satiricón, véase BURKART, 2017, p. 41-69; BURKART, Mara. O Pasquim y Satiricón ante la emancipación femenina. La prensa satírica de Argentina y Brasil a comienzos de los años setenta. In: PLAZA SANTIBÁÑEZ, Vicente (ed.). Dibujos que hablan: textos 2015-2016. Santiago: Consejo Nacional de la Cultura y de las Artes; Universidad de Santiago de Chile; Plop! Galería; Vicho Plaza, 2017b. p. 129-140; BURKART, Mara. De la libertad al infierno: la revista Satiricón 1972-1976. In: MALOSETTI COSTA, Laura; GENÉ, Marcela (comps.). Atrapados por la imagen: arte y política en la cultura impresa argentina. Buenos Aires: Edhasa, 2013, 307338.BURKART, Mara. Caricaturas de Perón en Satiricón, 1972-1974. Papeles de Trabajo, Buenos Aires, n. 7, p. 11-30, marzo 2011. Para el humor gráfico del diario Clarín, véase LEVÍN, Florencia. Humor político en tiempos de represión: Clarín, 1973-1983. Buenos Aires: Siglo XXI, 2013.
} 
a Marlene Pohle y a la periodista Cristina Wargon. Pohle hizo carrera como ilustradora y humorista gráfica en Europa y Wargon, colaboró con la revista HUM®. También, a partir de mediados de 1973, contó con Adelfa Correa como secretaria administrativa. Menos reconocimiento tuvo la participación en la revista de Sara Catán, la esposa de Cognigni que aparecía en los créditos como secretaria, pero varios colaboradores recuerdan que fue más que eso. Miguel Bravo Tedín (2001, p. 8) reconoce la centralidad de Catán en la elaboración de Hortensia: "muchas cosas de las que se publicarían en la primera década llevan, sin duda, su impronta o, más sutilmente, su inspiración porque así fue esta mujer de suave, participativa y coherente." Roberto Di Palma, el diagramador de Hortensia, recuerda que "Sarita es el gran motor [...] de la revista ¿no? el gran motor de la revista es Sarita Cognini, casi nadie se acuerda pero era el gran... aquello de que atrás de todo hombre... bueno, ésta era una pequeña gran mujer.” (DI PALMA, 2010. Información verbal) En Satiricón no hubo mujeres humoristas gráficas, aunque sí periodistas. Alicia Gallotti se destacó por sus reportajes audaces y sus notas sobre costumbrismo. Y tuvo varias colaboradoras mujeres, como Viviana Gómez Thorpe, por entonces esposa de Oskar Blotta, director de Satiricón.

\section{Trazo interrumpido I: Nelly Hoijman en Mengano, Siete días y Damas y Damitas}

En 1974, un grupo de colaboradores de Satiricón, disconformes con la línea editorial que esta había adoptado, renunciaron y crearon su propia publicación. Así nació Mengano, de Ediciones Julio Korn ${ }^{6}$ y dirigida por un triunvirato formado por Carlos Trillo, Alberto Bróccoli y Lorenzo Amengual. En su sexto número, en el sumario, Menganoscopio, anunciaron la aparición de Nelly Hoijman: "Una mujer-humorista ya es cosa curiosa, pero si además sabe mostrar las cosas desde un punto de vista femenino y relata a la perfección pequeñas historias de equilibrados valores, el asunto empieza a ser importante" (MENGANOSCOPIO, 1974 , p. 3). Su presencia era definida como algo fuera de lo habitual, revelando la

\footnotetext{
${ }^{6}$ La Editorial Julio Korn producía publicaciones periódicas y masivas de entretenimiento. En esa época se destacaban Radiolandia, Antena, Goles, Vosotras, TV Guía, Anteojito. Más información sobre Mengano, véase BURKART, 2017, p. 73-76.
} 
invisibilización de las mujeres que pasaron por la profesión con anterioridad. A su vez, decían apreciar de Hoijman la forma de narrar y que presentara valores "equilibrados" sin ampliar que entendían por esto último, aunque tal vez haya sido el modo de informar que no era feminista y que su humor no era satírico, es decir, que no usaba lo cómico como un arma. Nunca lo sabremos, pero sí sabemos que, pese a esta introducción auspiciosa, Mengano sólo publicó dos colaboraciones de Hoijman: la del número en que era presentada y la del número anterior, donde ya había publicado sin ser presentada. Nelly Hoijman dejó la revista cuando una de sus tiras salió publicada con cambios que no le habían sido informados y con los cuales quedó disconforme ${ }^{7}$ (HOIJMAN, 2018. Información verbal).

En ese entonces Hoijman era arquitecta -luego estudiaría psicología-, y comenzó a dibujar sus tiras a modo de pasatiempo, sus primeros lectores fueron sus compañeros de un curso de escenografía que estaba realizando. Publicó por primera vez un artículo en la Revista de Clarín y:

así fue como me enteré de cómo se publican las cosas, de casualidad se publican. Y ahí empecé a publicar unas cosas [...] y después ya se hace una cadena, conoces a uno y uno te dice '¿por qué no vas a tal lugar?' y fui a la editorial Abril, que en ese momento era la más importante. (HOIJMAN; 2018. Información verbal)

Entre 1974 y mediados de 1975, Hoijman publicó, además de en Mengano, en la revista Vosotras, también de Julio Korn editora, en Siete Días Ilustrados de la editorial Abril y en el Suplemento de Damas y Damitas de Ediciones Record; lo hizo como aficionada ya que no cobró por esas colaboraciones. Según ella, abandonó la tira "Donna" que tenía en Siete Días porque era muy demandante sostener una tira semanalmente, teniendo en cuenta que lo hacía ad honorem y que era una actividad secundaria ya que se dedicaba a la arquitectura. Sin embargo, muy probablemente también haya incidido en la decisión de la denuncia efectuada por Alejandro Balestrini, como veremos más adelante.

\footnotetext{
Se entrevistó también a Lorenzo Amengual pero no recuerda lo sucedido. Bróccoli falleció en 1985 y Trillo, en 2011
} 
En su paso por las redacciones, en especial por Abril, Hoijman recuerda haber conocido a muchos periodistas, varios de los cuales abandonaron la editorial cuando su dueño, el ítalo-argentino César Civita, fue perseguido, amenazado y sufrió un atentado de la Triple A (Alianza Argentina Anticomunista) bajo el gobierno peronista que lo obligó a irse del país (luego, bajo la dictadura militar, en 1977, Civita debió vender la empresa ${ }^{8}$ ). En cuanto al mundo de los dibujantes, era una "recién llegada" sin vínculos de amistad o parentesco con ellos o sus publicaciones, tampoco pasó por sus escuelas de formación. Hoijman nunca ingresó a sus espacios de sociabilidad y no logró permanecer en los laborales; más bien al contrario, fue expulsada de ellos. En marzo de 1975, El Tablero, la revista de la Asociación de Dibujantes de la Argentina (ADA) publicó una denuncia por estafa contra ella firmada por uno de sus afiliados, Alejandro Balestrini, que reclamaba ser co-autor de las tiras publicadas por ella. En la denuncia, Balestrini decía que Hoijman le había propuesto armar un equipo creativo, pero los trabajos fueron publicados sin su nombre.

Publicada en la sección "gremiales" se informaba que los representantes de la secretaría Gremial de la $\mathrm{ADA}^{9}$ se habían hecho presentes en la redacción de Mengano y habían podido "corroborar en los originales que la firma de Balestrini había sido tapada con tempera" (GREMIALES, 1975, p.4). ${ }^{10}$ El Tablero no decía nada más y, a diferencia de otras denuncias publicadas por el periódico donde había intervenido la justicia o donde la notificación informaba que el acusado había subsanado su falta, en ese caso, la versión del denunciante había sido suficiente.

Más de cuarenta años más tarde, preguntada Hoijman sobre su relación con Balestrini, nos explica que ella lo había contratado como dibujante para hacer detalles en el dibujo de sus tiras que a ella no le salían como quería: "ellos [los dibujantes, -porque Balestrini no fue el único-] tenían que hacerlo [al dibujo]

\footnotetext{
8 Sobre la editorial Abril, véase Eugenia SCARZANELLA (2016) y sobre la situación del campo cultural en aquellos años, BURKART, 2017, p. 111-131.

9 Las autoridades de la ADA eran Carlos Garaycochea (presidente) y una comisión formada por Horacio Altuna, Santiago Scannone, Graciela Goldsmidt, Alberto Broccoli, Caloi, y Domingo Mandrafina. De las reuniones también participaban Jorge Limura, Carlos Klillian y por poco tiempo lo hizo Miguel Brascó. [Agradezco a Domingo Mandrafina por suministrarme estos datos]. 10 Agradezco a Luchía Arturi el dato sobre la denuncia en la revista El Tablero.
} 
absolutamente idéntico [al borrador] pero con un dibujo profesional" (HOIJMAN, 2019. Información verbal). Hoijman aún posee sus bocetos, borradores y originales y en ellos queda demostrada su autoría y que Balestrini fue el dibujante de esas tiras (FIGURAS 1 y 2). También hay un par de láminas donde está la firma de Balestrini pero es evidente no había una dupla autoral: las firmas de cada uno están ubicadas en lugares diferentes, incluso, la de Balestrini pareciera que, por la ubicación, buscase pasar desapercibida y de hecho, Hoijman no sabía que esas firmas estaban allí (FIGURA 3). No hay mucha información sobre Alejandro Balestrini, lo que se sabe es que se dedicó a la pintura y que no hizo carrera en la historieta ni en el humor gráfico, y falleció en 2005¹. En las tiras publicadas en Siete Días y en Mengano, se nota la diferencia en el trazo de estos auxiliares contratados por Hoijman para mejorar su trabajo, en cambio el estilo de la humorada es el mismo.

Figura 1 - Boceto “Incomunicación”

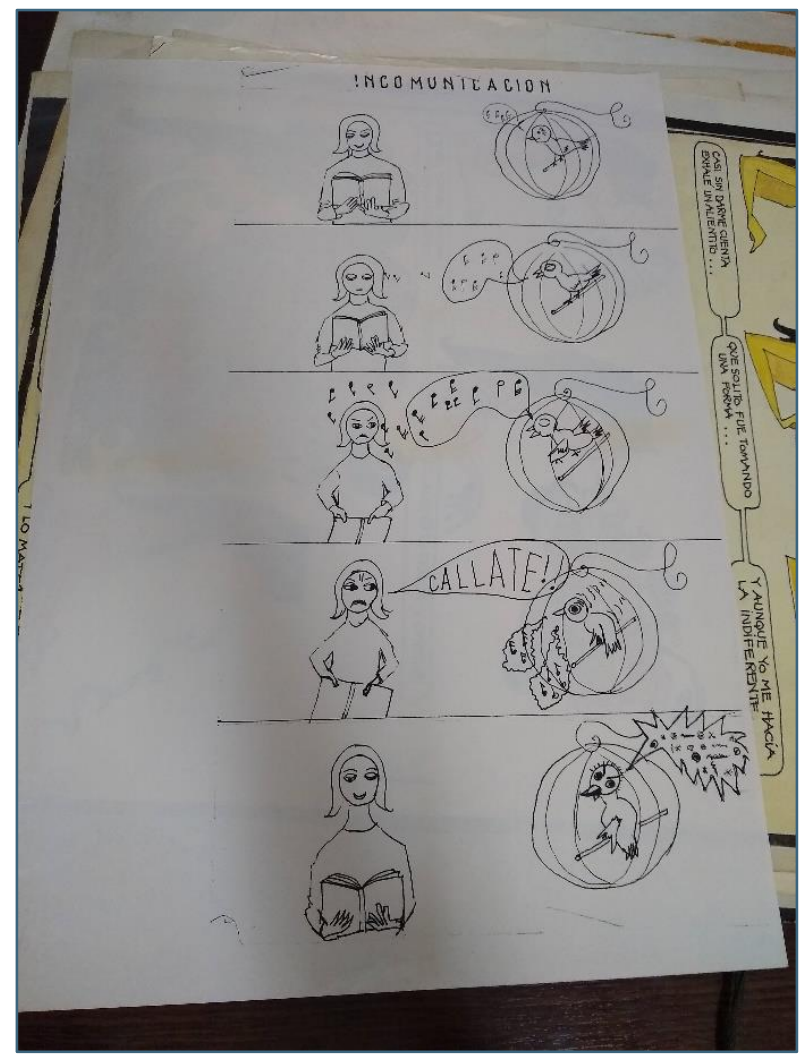

Fuente: Archivo personal de Nelly Hoijman
Figura 2 - Boceto firmado por Nelly Hoijman

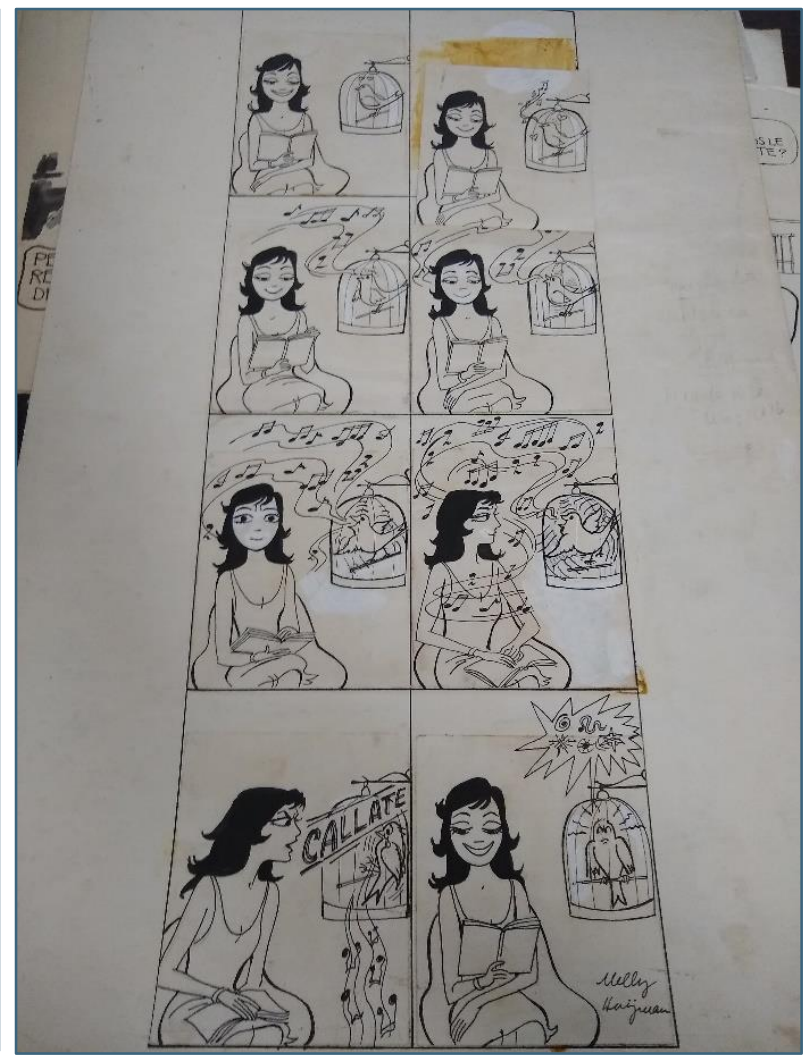

Fuente: Archivo personal de Nelly Hoijman

\footnotetext{
${ }^{1}$ En diciembre de 2019 contacté a través de Facebook a su hijo, Máximo Balestrini, y le pregunté sobre su padre y sobre la denuncia a Hoijman, me dijo no saber nada al respecto y que iba a averiguar con su madre y su tía, pero hasta el momento no me volvió a escribir.
} 
Figura 3- Versión firmada por Hoijman y por Balestrini

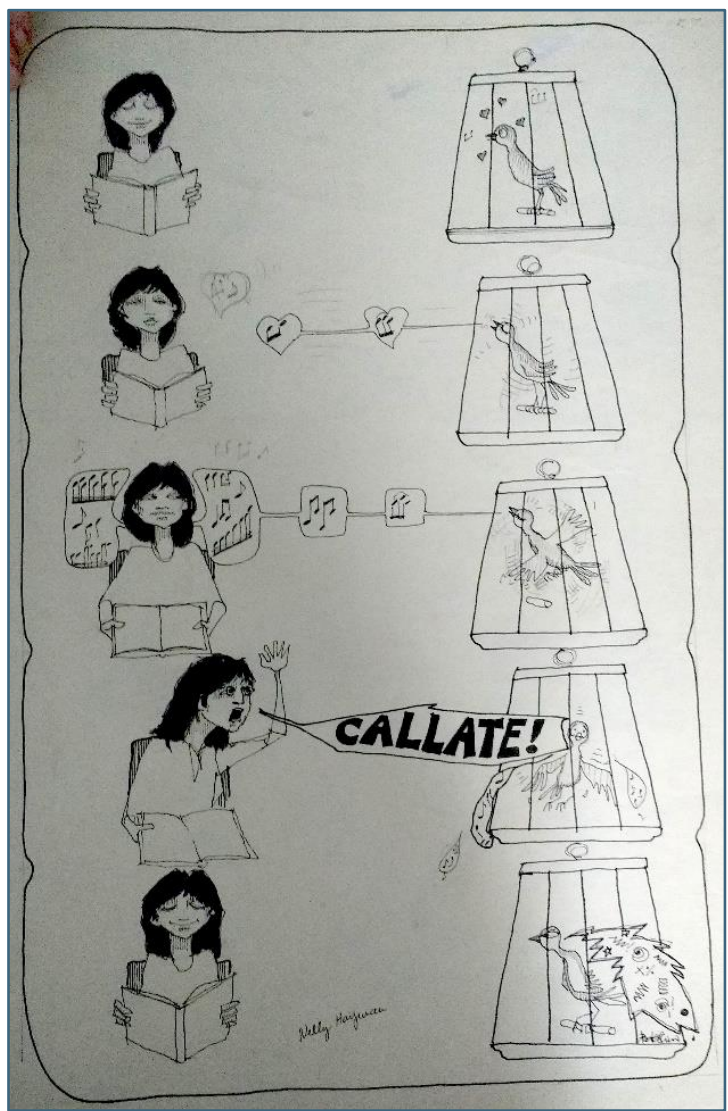

Fuente: Archivo personal de Nelly Hoijman

Así como Hoijman no se integró al mundo de los dibujantes, tampoco lo hizo al movimiento feminista que en esos años había avanzado en su organización: entre 1970 y 1975, apareció la Unión Feminista Argentina (UFA), Muchacha, Nueva Mujer y también se formaron el Movimiento de Liberación Femenina (MLF), el Movimiento Feminista Popular (Mofep) y la Asociación para la Liberación de la Mujer Argentina (ALMA), las cuales en 1975 se fundieron en el Frente de Lucha por la Mujer (FLM) (GIUNTA; 2018; ROSA, 2013; VASSALLO, 2005). Pese a haber alcanzado este nivel organizativo, el movimiento feminista no tenía una aceptación masiva ni siquiera entre sectores intelectuales de clase media. El feminismo era considerado como una reacción contra los varones y de ahí el estigma y los prejuicios tanto de varones como de mujeres. Nelly Hoijman no apostó por la acción colectiva, actuó de forma individual, y así como entró al mundo de la prensa gráfica y del humor gráfico, se fue. No respondió a la denuncia en su contra, se retiró y siguió con la arquitectura hasta que la empresa que tenía con su esposo fundió durante la última dictadura militar. Luego se dedicó a la psicología. 
¿En qué consistían las tiras de Hoijman? Con dibujos expresivos, despojados de escenografías, en los cuales la protagonista en primer plano interpelaba a los lectores con sus pensamientos y dudas, Hoijman nos introducía en un mundo femenino íntimo y sensible con el cual muchas mujeres podían identificarse. Nos presentaba a una joven bonita y enamoradiza, a veces culposa, que se esforzaba mucho por mostrarse feliz y alegre ante los demás, y que era ambivalente a la hora de sobrellevar el desamor. Así es que esta joven presentaba las "máscaras" que usaba ante los otros (HOIJMAN, 1974a, p. 8) (FIGURA 4); sugería que podía "atrapar a un hombre" con una rosa (HOIJMAN, 1974b, p. 14); creía haber olvidado a un amor pero no, a pesar de todo, este volvía a su mente (HOIJMAN, 1975b); en una cita, asistía a cómo un hombre se agrandaba o empequeñecía frente a una mujer enamorada (HOIJMAN, 1975c) o no podía evitar sentirse culpable ante el desaire de un hombre (HOIJMAN, 1975a) (FIGURA 5). Promovía así una risa indulgente entre las mujeres que habilitaba un proceso de autoconcientización y de afirmación.

Figura 4 - El humor tiene cara de mujer

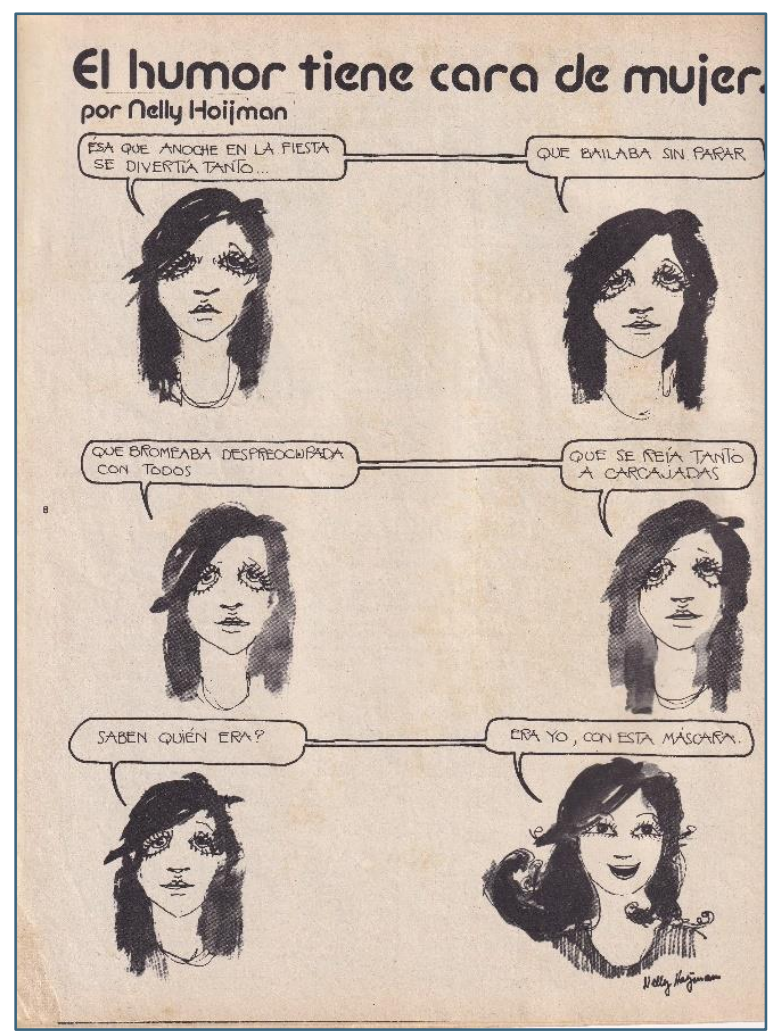

Fuente: HOIJMAN, 1974a, p. 8
Figura 5 - Donna

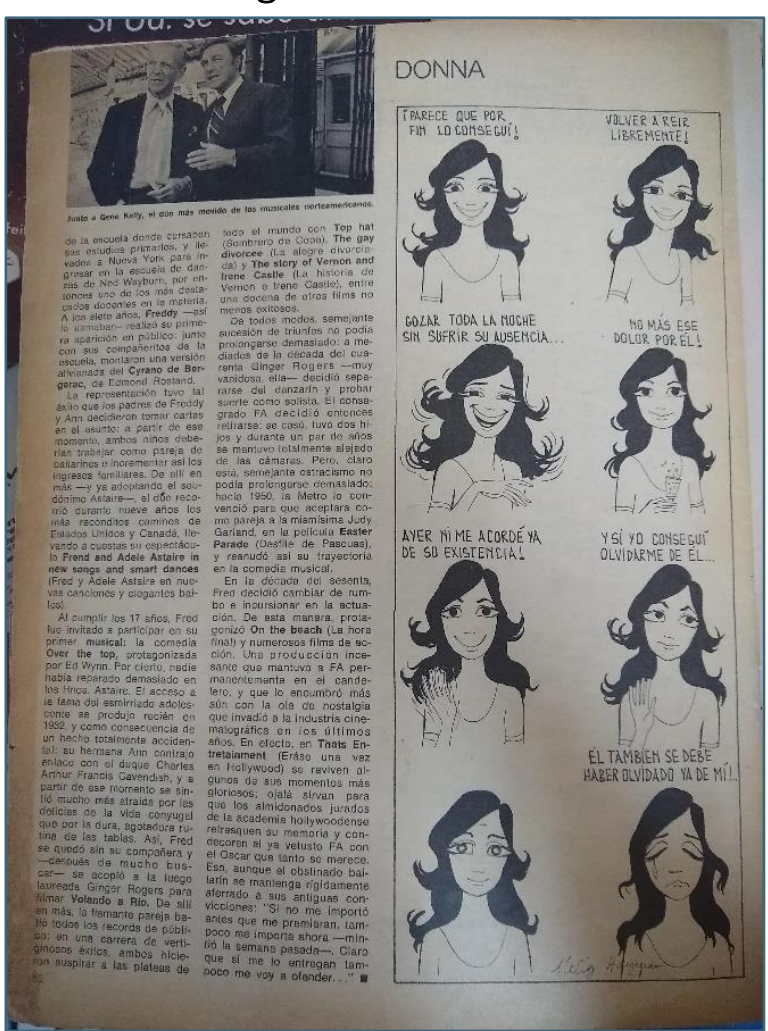

Fuente: HOIJMAN, 1975a 
Distinta fue la colaboración que hizo para la revista de mujeres Damas y Damitas, la cual no consistió en una tira humorística sino en una nota ilustrada en la cual daba consejos para las mujeres. Titulada “¿Qué buscan los hombres en las mujeres?”, la autora basaba su respuesta en el estadounidense Albert Ellis (1913-2007), "padre de la psicoterapia cognitivo-conductual y pionero de la intervención psicoterapéutica corta y directiva, que promulga la auto-ayuda" (LEGA; VELTEN, 2008, p. 189), además de sexólogo. Hoijman sostenía que se vivían nuevos tiempos en los que las enseñanzas que a las mujeres le habían inculcado sus madres y abuelas no funcionaba para armar una buena pareja ni para satisfacer los deseos y necesidades del "hombre de hoy". Lejos de propiciar transformaciones radicales en las relaciones de género, se trataba de darle voz y mayor participación a la mujer dentro del matrimonio. Hoijman explicaba que los "hombres de hoy" están muy "atareados", ya no son "ociosos playboys", por eso cuando piensan en casarse ya no:

Se derrite por la "frágil mujercita indefensa y un poco tonta" que lo necesita para resolver cualquier problema porque ellos son grandes y fuertes y ellas pequeñas e inútiles sino todo lo contrario [...] necesita una compañera que no lo frene en su progreso, capaz e inteligente para resolver los problemas cotidianos. (HOIJMAN, 1975d, p. 17).

Hoijman criticaba el romanticismo inmaduro y estéril de las "mujeresniñas", y reivindicaba las conversaciones inteligentes y el sexo en la pareja. Una mujer debía poder:

discutir una película, la situación del país, el cuidado y la alimentación de los niños, como preparar un buen puchero de gallina, o dónde invertir mejor el dinero para protegerse de la inflación. Pero que también sepa aceptar los errores de él sin censuras ni regaños. Una cosa es ser comprensiva e indulgente, compañera y consejera, y otra es ser competitiva, agresiva y regañona (HOIJMAN, 1975d, p. 18).

Es más, la mujer tenía que animarse a ser espontánea, inteligente, segura de sí misma para tener una pareja feliz y no "un marido tradicional y una pareja al estilo antiguo", lo cual era sinónimo de infelicidad y angustia. En definitiva, los consejos de la nota, que estaba acompañada por las imágenes de una pareja feliz en el Paraíso, comiendo manzanas y teniendo hijos, era una renovación de los 
atributos de las mujeres pero sin escapar de las relaciones machistas en el marco del patriarcado: se reconocía la superioridad del hombre sobre la mujer, la mujer debía acompañar y complacer al hombre, el espacio doméstico y de cuidado seguían siendo espacios exclusivamente femeninos mientras que el hombre era el sostén del hogar. Pese a estas limitaciones, se trataba de una invitación a las mujeres a empoderarse en el sentido de reforzar sus capacidades y protagonismo en el ámbito de la pareja.

Hoijman como humorista mujer ofreció personajes femeninos creados y perfilados por una mujer lo cual constituyó una novedad para la época. Su propuesta humorística promovía que las mujeres se rieran de sí mismas y en ese sentido podrían propiciar un cuestionamiento o desnaturalización del orden social vigente en cuanto a las relaciones de género. Esta posibilidad estaba incluso con sus limitaciones en la nota ilustrada que si bien no promovía cambios en el statu quo, buscaba ampliar los alcances de una realidad que hasta entonces se presentaba solo en mujeres de clase media, media-alta de ese entonces. Se buscaba así extender el modelo de la mujer universitaria o con algún tipo de formación profesional, heterosexual, casada y con hijos, que en los espacios de sociabilidad era percibida como par de los hombres pero sobre las cuales recaía la desigualdad laboral, el trabajo doméstico y las tareas de cuidado y crianza de los hijos.

La producción de Hoijman encontró buena recepción en el mundo de la prensa periódica ya que entre 1974 y 1975 publicó en tres revistas diferentes, algo que no volvió a ocurrir con una mujer por mucho tiempo: Mengano, Siete Días y Damas y Damitas. También generó la reacción machista, o incluso misógina, de Balestrini, quien a partir de la denuncia de fraude buscó su descrédito con éxito, ya que la ADA y los editores de Mengano le creyeron.

\section{Trazos interrumpidos II: Patricia Breccia y Lucy de Saccomanno en} HUM® (1979)

La revista $H U M \circledast$ apareció en junio de 1978, en medio del entusiasmo que generaba la realización del Campeonato Mundial de Fútbol en el país. Dirigida por Andrés Cascioli, reunía a los humoristas gráficos que se habían dispersado tras 
las clausuras de Satiricón y Mengano después del golpe de Estado de marzo de 1976 y del cierre de El Ratón de Occidente en 1977. Los editores de la flamante publicación habían advertido que, si bien se había producido una tenue distención en el régimen, aun imperaba la incertidumbre y que no estaban dadas las condiciones para una revista de humor político independiente de los dictados del mercado y de las facciones políticas. Sin embargo, asumieron el desafío con cautela y paciencia, y salieron airosos: la revista creció y avanzó en la construcción de su propia identidad e imagen pública (BURKART, 2017).

En abril de 1979, HUM® que inicialmente había tenido una periodicidad mensual pasó a ser quincenal, a tener más páginas por edición y a incorporar nuevos colaboradores, también mudó la redacción a unas oficinas más amplias. Entre los colaborados estables se destacaron dos mujeres que hicieron carrera allí: Gloria Guerrero, una joven que interpelará a sus coetáneos y Adelina "Mona” Moncalvillo, la reportera que reemplazó a Alicia Gallotti, que había migrado a España. Entre estas novedades, en julio de 1979 HUM® anunció "El "woman power" invade la historieta": Patricia Breccia y Lucy de Saccomano (Lucía Capozzo) se unían para darle vida a "Rita", protagonista de la tira "Rita y los oficios". Era toda una novedad para $H U M \otimes$ y para el mundo del humor gráfico y la historieta una dupla autoral compuesta por dos mujeres. La presentación, que generó la protesta de las autoras, incluía una foto de ambas y la descripción del nuevo personaje. Allí se informaba que ambas mujeres estaban vinculadas a hombres destacados del mundo de la historieta: Patricia era hija de Alberto y hermana de Enrique Breccia ${ }^{12}$, y Lucy era la esposa del entonces guionista y colaborador de HUM®, Guillermo Saccomanno.

La tira se le ocurrió a Lucía Capozzo, estaba inspirada en ella misma: en la dificultad que tenía con los trabajos, el hecho de ser polifacética y que se cansaba de las cosas y buscaba otras. Fue con la idea a su amiga Patricia, que ya despuntaba como gran dibujante. El nombre Rita fue por una amiga de la infancia

\footnotetext{
12 Lo que esa presentación no decía era que su hermana Cristina también se dedicaba a la ilustración, en ese entonces, había publicado láminas para revistas infantiles, tiempo después incursionó en la historieta en sociedad autoral con quien ese entonces fuera su marido, el guionista Norberto Buscaglia.
} 
de Patricia. Ambas, junto a la escritora y esposa de Carlos Trillo ${ }^{13}$, Ema Wolf conocían bien el mundo del humor gráfico y de la historieta de aquel entonces: a diferencia de Hoijman, ellas eran parte de las tertulias de los historietistas y allí eran tratadas como pares. Mujeres jóvenes, casadas y con hijos pequeños, lectoras, universitarias (Capozzo es socióloga y Wolf licenciada en Letras), con militancia política -en el caso de Lucía Capozzo-, y con opinión propia para hablar de la actualidad política y cultural, aunque sin cuestionamiento del orden patriarcal y sin contacto, incluso hasta con prejuicios hacia el movimiento feminista. Partícipe de esa sociabilidad, Capozzo recuerda que a los historietistas por ejemplo les encantaba Bretécher, mientras que criticaban duramente a las historietistas y humoristas locales: que la Hoijman era una neurótica, decían, e insinuando que el humor y la historieta "eran una cosa prohibida para el ámbito femenino." (CAPOZZO, 2020. Información verbal)

Lucía Capozzo le llevó la propuesta de la tira a Cascioli. Como no quería que nadie se enterara, se reunieron en un bar y no en su oficina. A Cascioli le gustó la propuesta y, además, es muy probable que haya visto el rédito de juntar a una Breccia y a una Saccomanno. También le sugirió ponerle texto a la tira y Capozzo recuerda hasta el día de hoy su respuesta: "el que escribe es Guillermo" (CAPOZZO, 2020. Información verbal). La introyección y naturalización del sometimiento de las mujeres a los hombres queda sintetizado en este temor de la autora a incursionar en un terreno, el de la historieta y el de la escritura, que lo percibe como vedado, es del marido y, como había señalado Hoijman en la nota que comentamos: la esposa no debe ser competitiva, debe ocupar un segundo plano. Como recuerda Capozzo:

no estaba instalado en nosotras el tema de los derechos de la mujer. Nosotras nos considerábamos nuestras en el sentido de que estábamos a la par de los hombres en la militancia, en esto y aquello, no nos cuestionábamos el lugar de la mujer. Había un statu quo y no se lo cuestionaba (CAPOZZO, 2020. Información verbal).

\footnotetext{
13 Trillo y Saccomanno se hicieron en los setentas y a partir de ahí establecimos una relación, primero de lectores y luego de guionistas. Compartieron la sección "El Club de la Historieta" en la revista Skorpio de editorial Record y en 1980 publicaron en coautoría Historia de la historieta argentina.
} 
Figura 6 - Nació una estrella: se llama Rita. ¡Socorro!

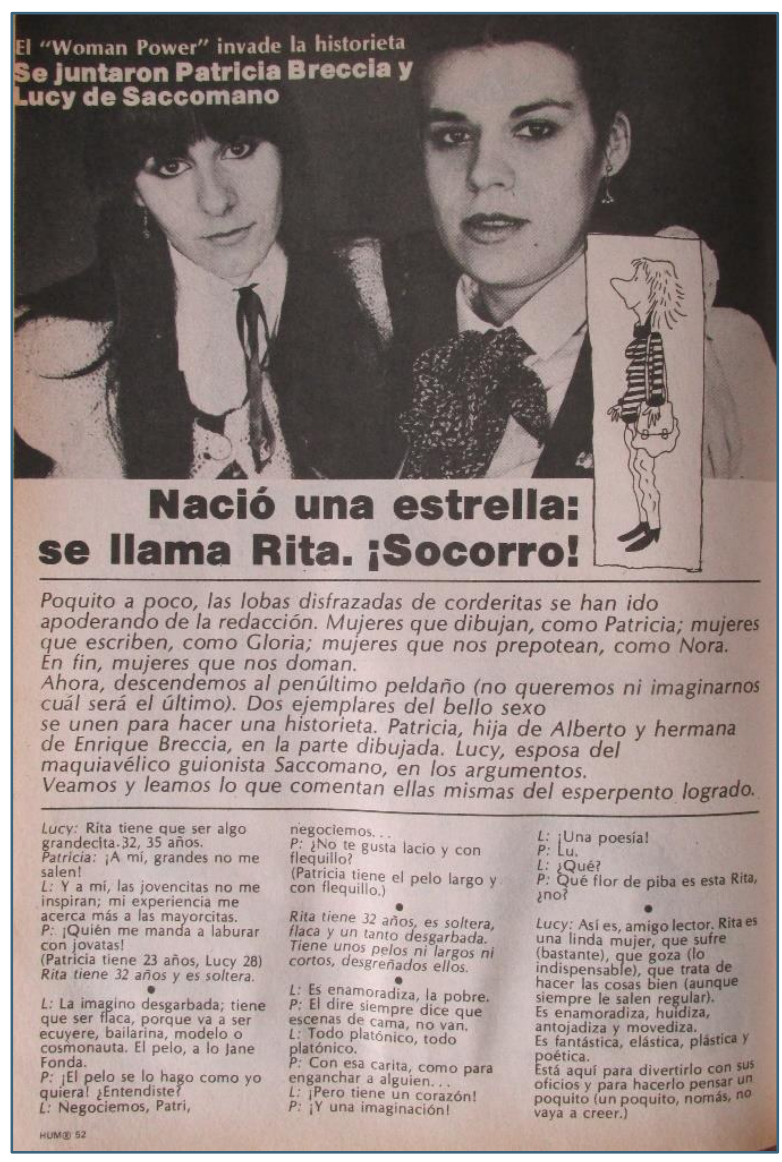

Fuente: NACIÓ..., 1979, p. 52

La presentación de las autoras de "Rita y los oficios", intentando ser graciosa, apelaba al machismo y revelaba la ambigüedad de una revista que en los hechos promovía una mayor presencia de mujeres en ámbitos mayoritariamente de varones, pero que se congraciaba con su lector ideal: el varón de clase media de unos cuarenta años de edad.

Poquito a poco, las lobas disfrazadas de corderitos se han ido apoderando de la redacción. Mujeres que dibujan, como Patricia [Breccia]; mujeres que escriben como Gloria [Guerrero], mujeres que nos prepotean, como Nora [Bonis, la secretaria]. En fin, mujeres que nos doman (NACIÓ..., 1979, p. 52).

Esta última frase traía a la memoria la controvertida idea de la mujer como opresora del varón, plasmada en el libro El varón domado que hizo célebre a la escritora Esther Vilar a comienzos de los años setenta. O mejor dicho, dejaba entrever que la relación de géneros es una relación de poder, el chiste está en definir quién es el dominante y quién el dominado. 
Rita, el personaje creado por Capozzo y Breccia, era una muchacha enamoradiza y muy tierna que estaba en la búsqueda de un oficio. En la presentación, las autoras dicen imaginar un lector varón y a este le propusieron: "divertirlo con [los] oficios [de Rita] y para hacerlo pensar un poquito..." a tono con la propuesta de la revista. También daban indicios de la autocensura imperante: "el dire [por Andrés Cascioli] siempre dice que escenas de cama, no van" (NACIÓ..., 1979, 52). Como todos sabían, se trataba de una de las estrategias de supervivencia de la revista más que una directiva de censura per se:

Había que evitar las referencias a [...] temáticas sexuales para que la revista no fuera considerada pornográfica, calificada de "inmoral" y clausurada. La experiencia acumulada con Satiricón, Chaupinela y El Ratón de Occidente había enseñado que frente a la censura legal era más fácil defender y conseguir adhesiones para una publicación política que para una calificada de pornográfica. (BURKART, 2017, p. 136-137)

De hecho, Patricia Breccia, como muchos otros autores que publicaron en $H U M \otimes$, reconocen que "Cascioli era un tipo que le daba una libertad increíble a sus colaboradores, al menos yo trabajé con él hasta el final, y jamás me censuró nada, y mucho menos me invisibilizó... Siempre trabajé con absoluta libertad" (BRECCIA, 2020. Información verbal).

La segunda entrega de "Rita y los oficios" tuvo el privilegio de ser publicada en color, que era un papel más caro. Esta vez, Rita trabaja en una fábrica, tiene una compañera con la cual pareciera que no se habla y ambas hacen un trabajo monótono frente a una máquina a la cual deben abastecer con un líquido. Sin embargo, Rita, a diferencia de su compañera, intercala ese trabajo con regar una flor y es así que esa planta crece en la máquina, y al abrirla descubre un mundo campestre soleado y colorido por donde termina escabulléndose (CAPOZZO; BRECCIA, 1979, p. 46) (FIGURA 7). Si bien no fue concebida como una crítica a la dictadura militar que gobernada desde marzo de 1976, era una metáfora crítica del tedio que imperaba en la vida cotidiana bajo la dictadura militar, tan denunciado por los lectores de $H U M \otimes$. 
Figura 7 - Rita y los oficios

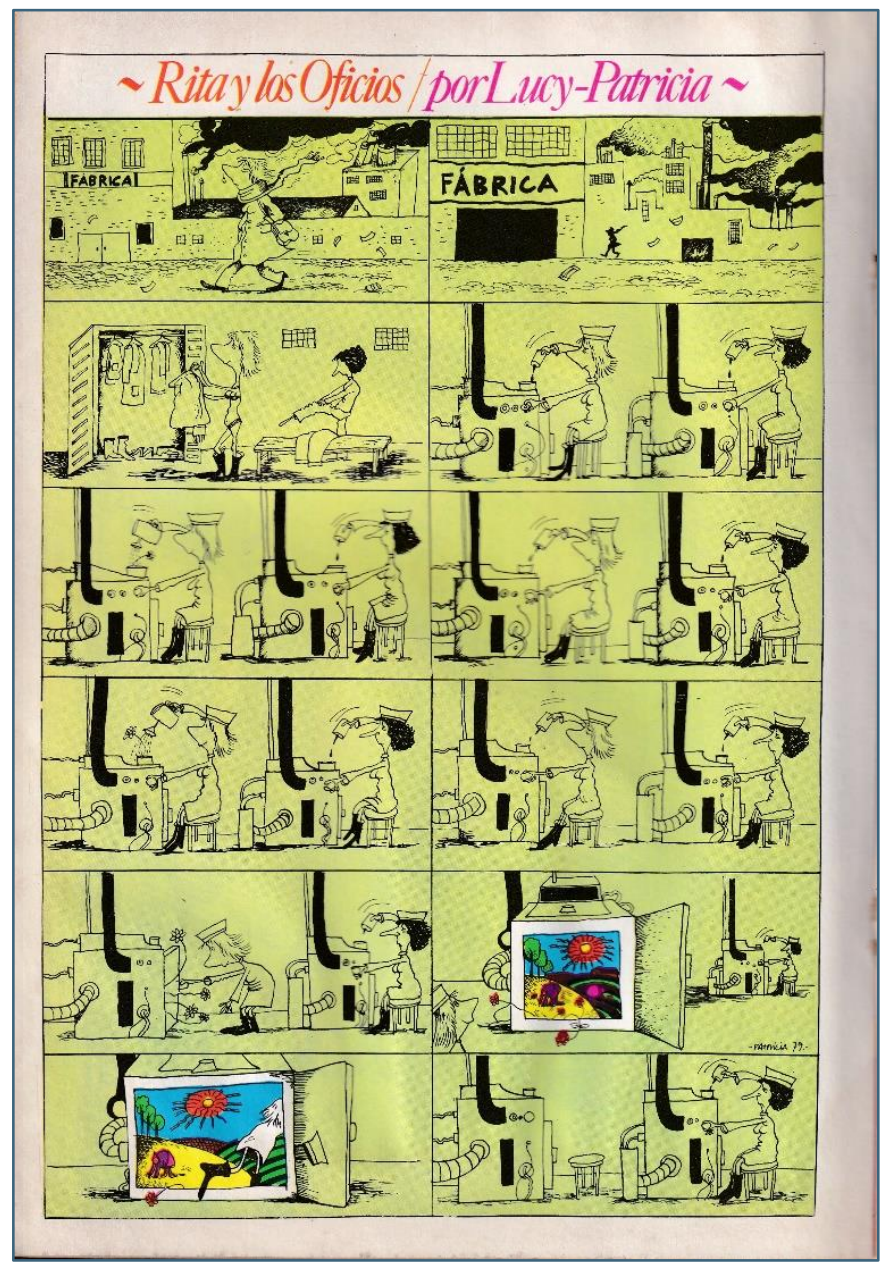

Fuente: CAPOZZO; BRECCIA, 1979, p. 46

Pese a ajustarse a la auspiciosa introducción y a las expectativas puestas en la incursión de estas mujeres en un terreno dominado por hombres, "Rita y los oficios" tuvo apenas cuatro entregas. Lucía Capozzo recuerda que fue Patricia la que decidió no seguir y ella no quiso hacerla con otro dibujante. Breccia, por su parte, recuerda que

Los lectores nos mataban en la sección de "Carta para lectores". Imaginate, dos minas haciendo una tira. No lo soportaban. Creo que nos aburrimos de hacerla. Ya no me acuerdo si fue ella [Lucía Capozzo], las dos, o yo que decidí cortarla. Pero te aseguro que el Tano Cascioli no fue. (BRECCIA, 2020. Información verbal)

En efecto, en el número 18 de $H U M \Theta$ una lectora criticaba que la revista había decaído en calidad: "ustedes llegaron a un punto de ser tan, tan, tan buenos que se pueden permitir bajar la puntería y ser tan, tan bueno, y seguir bajando [...] pero ¡ojo!! Que hasta sus más caras admiradoras y enamoradas nos 
percatamos" (EL PAVOROSO..., 1979, p. 13). La lectora identificada como Cristina Moyano primero propuso reemplazar a Gloria Guerrero y luego preguntaba “¿Qué significa ese engendro de Lucy-Patricia???? ¡Esas chicas no saben ni posar para la foto! Si estos tres ejemplares es lo mejorcito que conocen, debo decirles que tienen bastante poco mundo." Y después de celebrar a varios colaboradores varones, concluye su misiva: "Uno los quiere mucho, pero...ojo con las debilidades con el sector femenino" (EL PAVOROSO..., 1979, p. 13). En el número siguiente era un lector varón, Carlos S. Kedinger, quien criticaba a esta dupla autoral. Después de reprocharle otros aspectos a la revista dice:

ni los vínculos familiares ni la amistad justifican haber incluido a esa pareja de pavotas obviamente incapaces de escribir o dibujar decentemente [...] Mejor que la Patricia aprenda a cocinar y la Lucía a lavar los platos. El humor, además, es una de esas cosas vedadas a la mujer, como la pintura, la creación musical o bajarse del colectivo en movimiento. Me extraña tanto nepotismo al divino cuete [...] Además, publicar esos garabatos infames es ofender a talentos como Fati, Oski, Crist, Gondona White, Ceo y otros. Uno no paga 2.500 sopardos cada dos semanas para aguantar tipas mediocres. (SADOMASOQUISTA..., 1979, 13)

Sin defender a sus colaboradoras, desde la redacción le respondieron: "Aflojá un poco la mano, Carlos S. Después de todo, si la revista te parece tan espantosa, en vez de flagelarte con su lectura podrías recomendársela a tus enemigos" (SADOMASOQUISTA..., 1979, 13).

Patricia Breccia recuerda aún hoy esas cartas: "Nos mandaban, literalmente, a lavar los platos. Me acuerdo perfectamente. Y no creo que la hayamos cortado por eso, nos hacía gracia, por lo menos a mí, supongo que habrá pasado otra cosa..." (BRECCIA; 2020. Información verbal). Ni el tenor de la crítica ni el nivel de agresividad en los comentarios eran excepcionales, muchos lectores escribían en esos tonos sus críticas a la revista como se aprecia leyendo la sección "Quemá esas cartas” y se respondía sin enojo, sino más bien con ironía. En todo caso, lo que sobresalía en las cartas que citamos es el machismo y el sexismo arraigado y convertido en sentido común que impregnaba a hombres y mujeres, y revelaba que el orden patriarcal estaba encarnado por mujeres. Por un lado, se sospechaba de nepotismo, por otro, de la seducción ejercida por mujeres, ninguno de estos lectores daba crédito a la creatividad y al talento de estas mujeres. En el caso de estas mujeres, los vínculos familiares, matrimoniales 
o de amistad sólo se entendían de modo negativo, estableciendo implícitamente una doble vara e ignorando que muchos hombres también publicaron por primera vez gracias a los espacios que un padre ${ }^{14}$ o un amigo les abrió (siendo más excepcionales, si los hubiera, espacios equivalentes abiertos o habilitados por madres o esposas).

No volvieron a trabajar juntas, Patricia Breccia hizo carrera como dibujante, aunque más volcada a la historieta que al humor gráfico, aunque hacia fines de los años noventa publicó "El gran Zoo" en $H U M \otimes$, una tira que satirizaba a la televisión argentina y a sus actores. Entre 1980 y 1982, publicó "Sol de Noche”, una historieta con guión de Guillermo Saccomanno, en la flamante SuperHUM®15. Si bien a comienzos de los setenta, Breccia había trabajado de cadete para Satiricón, la revista en la cual Cascioli había sido director de Arte, y eso le sirvió para conocer a la gente que allí trabajaba; el ingreso de Patricia Breccia al mundo editorial fue por los contactos de su padre:

La posibilidad de publicar se dio naturalmente porque yo siempre estaba donde estaba mi viejo, él me llevaba con gusto, y yo lo acompañaba feliz. Pero claro, eso no significó que se me abrieran las puertas mágicamente, se me exigía más por ser la hija "de". Y por ese motivo (y otros) tuve que pagar un derecho de piso casi eterno... (BRECCIA, 2012).

En este relato se advierte que el ser "hija de" no significó que las cosas le hayan sido facilitadas a Patricia Breccia. En el caso de los Breccia, si bien la transmisión de la profesión artística de padres a hijos ya no era considerado socialmente la norma, tampoco era atípico y ciertamente la institución familia en este caso funcionó de modo alentador para que Patricia se iniciara en este arte y en la profesión. Ser parte de una "familia de artistas" (Breccia) o ser esposa de un escritor (Capozzo), les permitió a estas mujeres incursionar e iniciarse en el campo del humor y la historieta, participar de los espacios laborales y de sociabilidad pero su ingreso y su permanencia como profesionales revelan obstáculos que evidencian las relaciones de género, el poder presente en las relaciones entre lo que culturalmente se considera como propio de una mujer y

\footnotetext{
14 A Enrique Breccia no se lo acusó de nepotismo, por ejemplo.

${ }^{15}$ En 2012, esta historieta fue compilada por La Duendes.
} 
de un varón (Nochlin, 2001). Lucía Capozzo no provenía de una familia de artistas sino de familia con una empresa de calzados exitosa, como ya dijimos, siguió una carrera universitaria y luego, se destacó (y aún lo hace) como periodista radial, pero ha tenido diversos trabajos, incluso con altos grados de responsabilidad. Gran manejadora de la palabra oral, reconoce una deuda con la escritura.

En $H U M \Theta$, a los pocos meses del fin de "Rita y los oficios", en diciembre de 1979, Claire Bretécher, fue presentada. Aunque tal vez algún lector haya tenido oportunidad de escuchar su nombre en 1978 cuando pasó por Buenos Aires la compañía de danza francesa Théâtre du Silence con la versión en mimo-danza de "El cordón infernal", obra maestra de Bretécher. Otros tal vez hayan visto algún trabajo suyo expuesto en la Primera Bienal Internacional de Historieta y Cuarta Argentina del Humor y la Historieta que se realizó entre el 25 de mayo y el 17 de junio de 1979, en el Museo Genaro Pérez de la ciudad de Córdoba. Es muy probable que Andrés Cascioli haya adquirido los derechos de sus tiras mientras organizaba dicho evento. Entre 1979 y 1984, HUM® reprodujo entregas de la saga "Salades de saison" ("Ensaladas de temporada"), publicada en Francia en 1973. Su presencia en $H U M \Theta$ fue continua, se interrumpió por un año entre 1981 y 1982 , cuando en su lugar se publicaron las tiras de Marta Vicente con un estilo estético y humorístico tributario de la francesa que advertía la huella que estaba dejando en la Argentina.

\section{Trazos interrumpidos III: Marta Vicente en HUM® (1981-1982)}

Marta Vicente nació en 1952 en la ciudad de Mendoza, Argentina. Formada en Bellas Artes en la Universidad Nacional de Cuyo y esposa de Luis Scafati, conocido como Fati por los lectores de $H U M \Theta$, Marta Vicente no hizo carrera dentro del humor gráfico. En 1982, dejó de publicar cuando quedó embarazada de su tercer hijo, y después de 1984 volvió a hacerlo por un breve período en la revista Fierro. Posteriormente, retomó su carrera de artista plástica pero alejada del humor y la historieta (VICENTE; 2017. Información verbal). Tampoco Scafati se dedicó al humor, de hecho, sus colaboraciones en $\mathrm{HUM}{ }^{\circledR}$ pasaron a ser más bien ilustraciones que acompañaban a las notas escritas, aunque continuó firmando con su seudónimo. Luis Scafati junto a su esposa son una pareja de 
artistas, es decir, "llevan una vida creativa en compañía” pero cada cual hizo su propia trayectoria con su propio estilo (CHADWICK; DE COURTIVRON, 1994, p. 14).

Cuando comenzó a publicar en $H U M \Theta$, en marzo de 1981, el país y la revista estaban atravesando una coyuntura álgida: a nivel nacional, la asunción del general Roberto Viola a la presidencia de la Nación había generado un clima ambiguo que combinaba expectativas con cinismo y desconfianza hacia posibles cambios. La revista, por su parte, asistía a un acelerado proceso de consolidación y politización:

Sus editores estaban ávidos de interpretar la llegada de Viola al poder como una posibilidad de profundizar y extender aquella grieta en la coraza impuesta por la dictadura (esa misma grieta que había habilitado el surgimiento de la revista en 1978), y actuar en consecuencia. (BURKART, 2017, p. 209).

Este afianzamiento de $H U M \otimes$ no pasó desapercibido entre sus detractores. El número donde Marta Vicente publicó por primera vez, incluía un editorial titulado "La Intolerancia" que denunciaba a las revistas Cabildo, Línea y el diario bahiense La Nueva Provincia. La primera había definido a HUM® de "subversivos y marxistas", la segunda, de "comerciantes y oficialistas" y el tercero, la acusaba de promover el nihilismo entre los jóvenes (LA INTOLERANCIA..., 1981, p. 5).

A diferencia de Bretécher, Breccia y Capozzo, la incorporación de Marta Vicente no fue anunciada, el lector encontraba su tira al llegar a la página 48 y nada se decía sobre su relación con Fati. La primera entrega se tituló "Humor femenino": el énfasis estaba en la cuestión de género y evitaba una definición más fuerte y controvertida como la que hubiese sido "humor feminista" justo en un número que publicaba la nota "Elogio y defensa del machismo" de Santiago Varela (1981, p. 35-36). Escrita con tono jocoso, habitual en $H U M \otimes$, esta nota de opinión sostenía que el machismo fue inventado y era defendido y promovido por las mismas mujeres. El humorista acuñaba la palabra "hembrismo" para referirse al comportamiento de las mujeres que refuerzan las prácticas machistas:

el machismo prospera gracias a un amplio espectro en la población femenina que cultiva a diario distintas formas de hembrismo que hacen posible su existencia. (Una vez más los hombres pasamos a ser inocentes víctimas de maquiavélicas artimañas). (VARELA, 1981, p. 35). 
El fenómeno por el cual las mujeres aparecen como defensoras del patriarcado lo advertimos en el apartado anterior al analizar la crítica de la lectora a las autoras de la tira "Rita y los oficios" y ese mismo tema reaparecía en la primera tira de Vicente, que dialogaba críticamente con la nota de Varela. "Humor femenino" retrata una situación cotidiana de un matrimonio de mediana edad y de clase media: el hombre, con anteojos, lee el diario sentado en un cómodo sillón mientras su esposa, de cuerpo fornido y delantal, ama de casa, barre el piso y comenta:

¿Qué no son machistas? En este país todos son machistas. Mirá ese loco que tiró la mujer por la ventana... lo invitaron a comer en la tele, le hicieron reportajes en las revistas... hizo la temporada en Mar del Plata y hasta salió una vedette que dice estar perdidamente enamorada. iiMachistas!! (VICENTE, 1981a, p. 48).

El marido la escucha pero no responde, sigue leyendo el diario hasta que levanta la vista y mira con simpatía hacia la ventana como deseando hacer lo mismo que ese hombre del cual habla su esposa. (FIGURA 8).

Figura 8 - Humor femenino

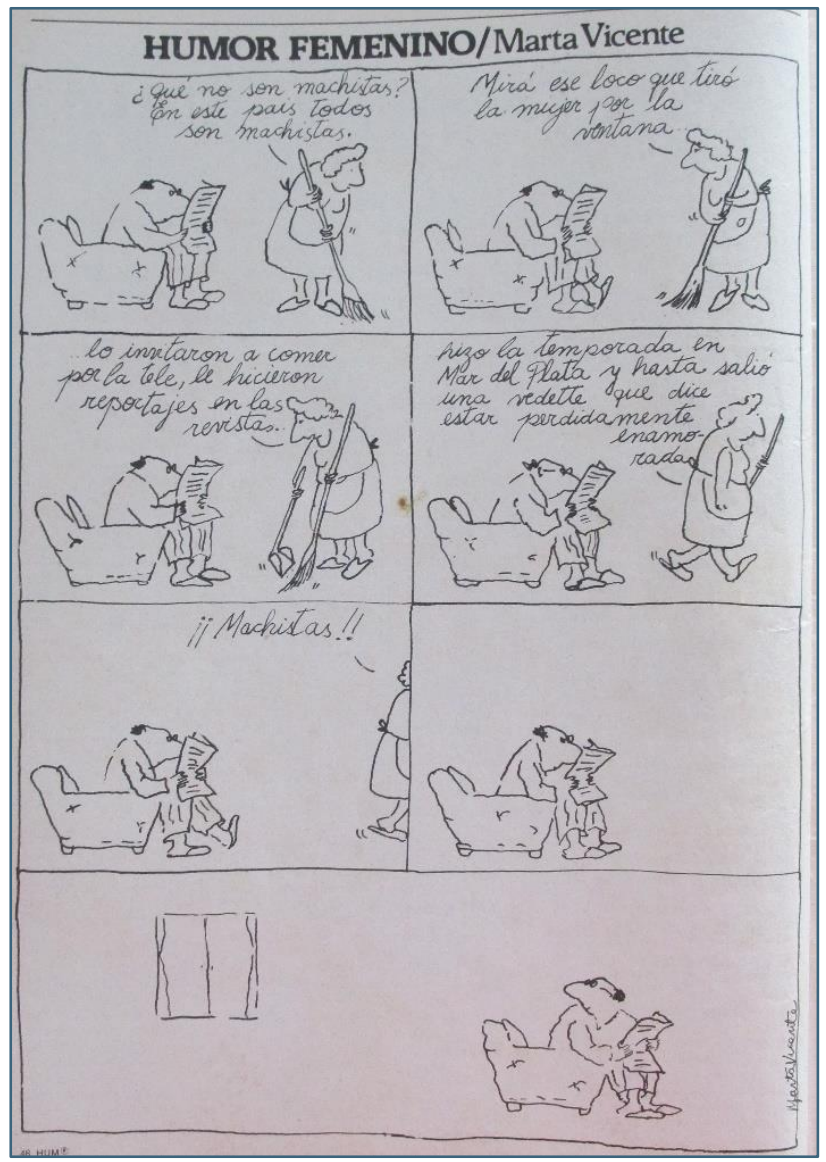

Fuente: VICENTE, 1981a, p. 48 
La tira de Marta Vicente no sólo decía que machistas podían ser todos, hombres y mujeres, sino que además criticaba la naturalización de la violencia de género más extrema, lo que hoy denominamos femicidio o feminicidio, y el tratamiento mediático de los victimarios por el cual estos no eran condenados socialmente sino más bien reivindicados y celebrados. La tira criticaba lo que señala Susana Velázquez (2003, p. 23) sobre la visibilidad de los hechos violentos en los medios de comunicación, cuando estos se imponen como espectáculo: la narración ostentosa, casi obscena promueve "una hipertrofia del escuchar y del ver, una tendencia voyeurista de fascinación de quienes asisten 'pasivamente' a las violencias padecidas y ejercidas." Vicente proponía una distancia crítica con respecto a esa tendencia de la televisión que cambiaba de lugar a la violencia y la introducía en la vida de quienes la miraban o la escuchaban de forma "domesticada y convertida en objeto que se puede tolerar y consumir, la violencia queda neutralizada, anulándose en muchas personas, su carga negativa y la censura" (VELAZQUEZ, 2003, p.23) Por último, alertaba sobre la intolerancia de los varones hacia quienes cuestionaran sus privilegios: la denuncia del machismo incentivaba en los hombres las ganas de deshacerse de las mujeres, de "tirarlas por la ventana”.

Pero no era solo la televisión la que celebraba a los hombres violentos, el humor gráfico también reproducía chistes machistas y sexistas que hoy no podrían publicarse porque los umbrales de tolerancia hacia la violencia de género, la violación o el femicidio cambiaron. En el mismo número que salía la nota de Varela y "Humor femenino" de Vicente se publicó un chiste de Cilento (1981, p. 14) (FIGURA 9) que muestra una comisaría donde hay dos ventanillas para "Violaciones", la de "denuncias" y la de "solicitudes", es en esta última donde hay más mujeres esperando a ser atendidas. Chistes como estos no eran una novedad, incluso en revistas como Satiricón ya se habían publicado chistes que minimizaban las violaciones de mujeres al sugerir que las mujeres deseaban ser violadas ${ }^{16}$ y chistes sobre acoso callejero.

\footnotetext{
16 Por ejemplo, la tira de Rafael (Satiricón, 1973) en la cual una mujer cae en un pozo donde había "hombres trabajando", sale confundida y golpeada, el comenta a otras mujeres lo que le sucedió (la tira es muda pero se entiende que la violaron) y estas, entusiasmadas, hacen fila para meterse al pozo.
} 
Figura $9-\sin$ título

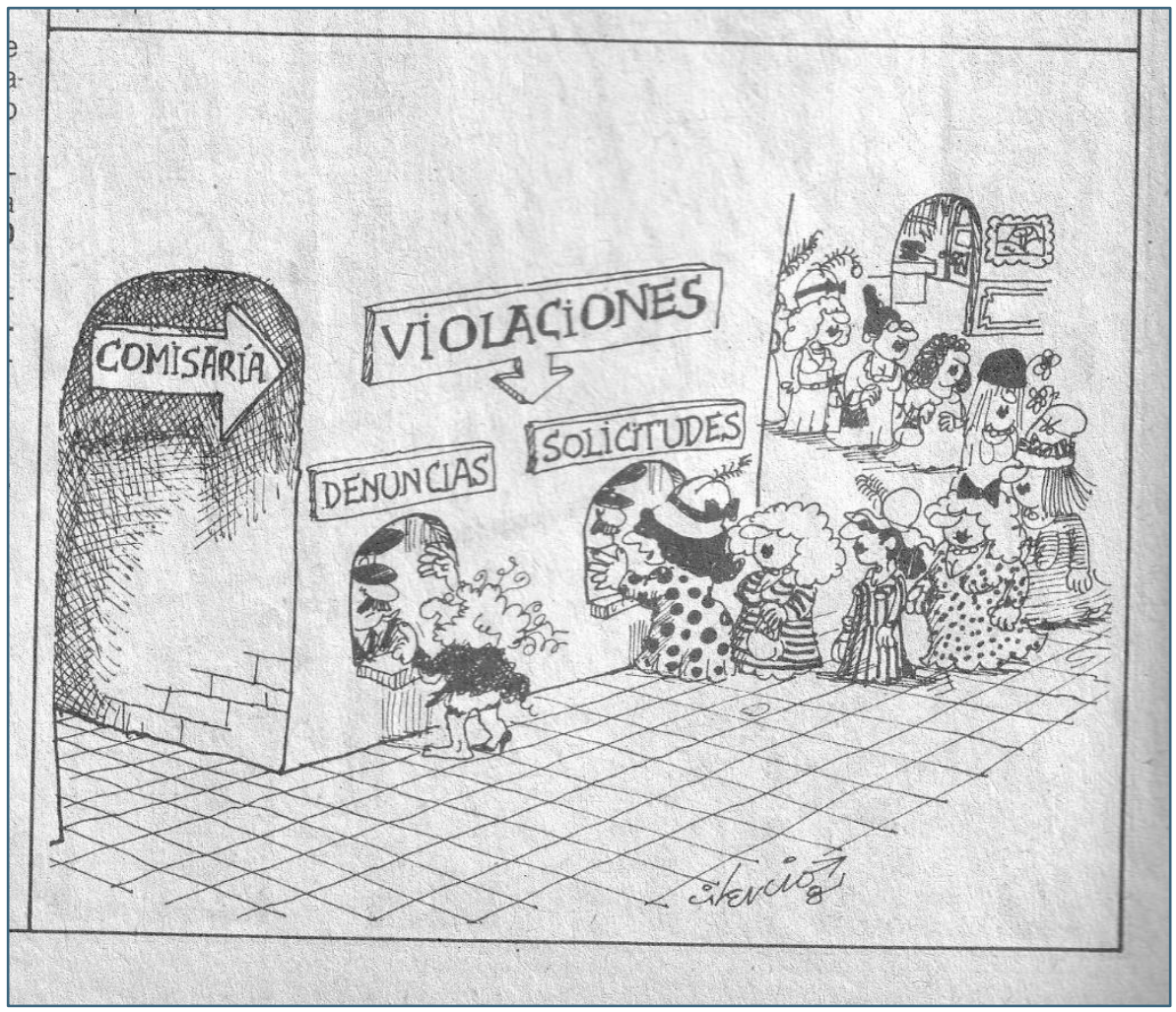

Fuente: CILENTO, 1981, p. 14

En el humor gráfico las representaciones de las relaciones de género son un topos habitual, en especial en lo que se denomina humor costumbrista, el cual tuvo un importante despliegue en los primeros años de HUM®. Unas páginas antes de la flamante tira de Vicente se encuentra la tira "Comedia de(s)parejas" de Eduardo Maicas (guión) y Buttafuoco (dibujo) (1981, p. 34) que presentaba otra situación doméstica de un matrimonio joven de clase media. Allí vemos a la esposa entrar a la casa cargada con las compras mientras su marido estaba sentado en el sillón del living también leyendo el diario. Él le pide que se le acerque para comentarle las noticias y ella responde con enojo que se acerque él, que ella está ocupada; él le pregunta por qué está "nerviosa”, ella le contesta pero él no le cree y le dice "te debe estar pasando otra cosa" a lo que ella responde "Es muy fácil decir que estoy nerviosa mientras se lee el diario como un bacán... una en cambio no puede parar ni un minuto" debido a todas las tareas domésticas. El marido le propone solucionar el tema contratando a una mujer para que la ayude y ella se niega: "Estas loco, para que esté metida todo el santo día entre los dos y no podamos hablar nunca" (MAICAS; BUTTAFOUCO, 1981, p. 34). La tira ponía el foco en el trabajo doméstico y en el agobio que le generaba 
a la protagonista pero, como en la tira de Vicente, no había un cuestionamiento a la división sexual del trabajo, las tareas domésticas correspondían a las mujeres: a la esposa o a una empleada. Había una representación positiva del varón, este era el que aportaba la solución, mientras que la mujer cargaba con la imagen negativa: era la caprichosa, la quejosa que rechazaba el supuesto alivio. No se proponía otra salida como sería que el varón dejase de ser un "bacán" y ayude a su esposa con las tareas domésticas. Como el título de la tira indica era una "comedia despareja".

En los siguientes números, las cuestiones de género fueron temas de otras notas: en la sección “Nada se pierde”, Sandra Russo (1981, p. 6-7), por entonces correctora de estilo, denunciaba lo que hoy está tipificado como acoso callejero. Ella habla de "hombres-mosquito" para aludir a los varones que "suponen que todo objeto femenino sin compañía está anhelando escuchar sus zumbidos y recibir algunos de sus picotazos." Russo narraba sus vacaciones en la costa argentina y concluía que en la Argentina "una mujer no puede veranear sola", había "aprendido" que "el magnífico súper yo de la población masculina le tiene vedado a una joven formal disfrutar en paz del mar, o de una caminata. Que la soledad de una mujer equivale, en este país, a tener un cartel en la frente que dice: “vacante, busca macho” y preguntaba “¿Quién les dijo que una mujer siempre tiene ganas de escucharlos, de conocerlos, de que la acompañen, de que la sigan balbuceando estupideces? ¿De dónde sacaron que cualquiera y en todo momento debe levantarse a alguien o dejarse levantar?" Finalizaba diciendo que el suyo no era un alegato feminista como si asumirse feminista desmereciera la crítica que estaba haciendo.

Y, en el número 56, Silvia Puente y Cristina Noble (1981, p. 53-55) le respondieron a Santiago Varela. El título de la nota, "Dos mujeres contra todos", buscaba ser gracioso, pero aludía a la posición de minoría que representaban. Una nueva viñeta de Cilento ilustraba la primera página de la nota: una mujer química le explicaba a un colega una compleja fórmula y el hombre lo único que pensaba era en los pechos de quien le hablaba. La mirada masculina sobre las mujeres seguía imperando en la revista. Ambas periodistas reconocían que se están viviendo cambios en las relaciones de género y lo atribuían a su aumento en el mercado laboral. Silvia Puente argumentaba que ese incremento no resolvió 
la situación desigual de la mujer debido a que aún no se contemplaba al trabajo doméstico en las estadísticas sobre trabajo productivo. Esa desigualdad se daba, según su explicación, por un lado, porque aquellas que trabajaban fuera de su casa seguían siendo responsables de las tareas domésticas y de cuidado de sus hijos y, por otro, por el salario: las mujeres debían aceptar que le ofrecieran menor paga que a un hombre. Estas desigualdades se sostenían por "tradición" y por un sentido común arraigado que conservaba el statu quo y se expresaba en frases hechas como "estar 'a los pies' de nuestros maridos”, "la mujer si quiere vivir bien que se case, que busque un buen partido", "Seguro que trabaja porque no le gusta la casa”, “¿Por qué no te vas a lavar los platos?”

El problema no era únicamente con el trabajo, señalaba Silvia Puente, sino también la desigualdad en materia de derechos civiles: sólo los varones tenían patria potestad sobre sus hijos (la patria potestad compartida se aplicó recién en 2015 con el nuevo Código Civil), las empresas no empleaban mujeres porque "son más faltadoras", los médicos y enfermeras solían maltratar a las mujeres embarazadas en lo que hoy conocemos como violencia obstétrica. La enumeración incluía también al acoso callejero y al hecho de que las mujeres solteras pasaran a "convertirse en la "loca" del pueblo" o la "rayada", que "las revistas nos ponen en exhibición [...] Cuentan secretas historias de amantes, o penas de princesas abandonadas (las mujeres se siguen dividiendo en dos grupos)" (PUENTE; NOBLE, 1981, p. 53-54). y esto no era porque faltasen mujeres en los medios de comunicación, "hay muchas, aunque podría haber más. Pero, o son responsables de la edición de materiales anti-femeninos o son tildadas de feministas, como quien dijera, aliadas de Satán" (PUENTE; NOBLE, 1981, p. 53-54). También imperaba la construcción binaria de los géneros:

Las mujeres estudiamos SER MUJER como un versito, y los varones SER HOMBRE, de la misma manera. Los hombres no lloran, las mujeres sí [...]; los hombres son rudos, las mujeres suaves; ellos intelectuales, ellas afectivas; ellos fuertes, ellas frágiles; él activo, ella pasiva; él generoso, ella envidiosa; él polígamo, ella monógama; él experimentado en el amor, ella virgen; él infiel, ella fiel; sádico, masoquista; obsesivo, histérica. (PUENTE; NOBLE, 1981, p. 54)

Cristina Noble, por su parte, le respondió a Santiago Varela que su teoría equivalía a "afirmar que a los nazis los crearon los judíos", y se refirió a las 
fricciones, malos entendidos y a las reacciones conservadoras que generó en hombres y en mujeres el aumento de estas últimas en puestos y oficios antes destinados a los varones. Sin apelar a la noción de género, la autora, en la misma línea que Silvia Puente, aludió a la construcción social del género, incluso:

¿Cómo no explicarse que la cuestión sea irritativa y difícil, si está entrelazada como una telaraña a nuestros sentimientos, vida y pesadillas infantiles? [...] Crecimos separados por rígidas normas morales que convertían en sórdido el interés normal por acercarnos al otro, a su cuerpo o sentimientos. (PUENTE; NOBLE, 1981, p. 55)

Y cerraba su nota rechazando a quienes buscaban chivos expiatorios, como Santiago Varela y como las feministas "vulgares" que decían que "los hombres son los responsables de este estado castrador que padecemos"; y promoviendo, en cambio, "la síntesis, la reconciliación interna, en cada una (o uno) de nuestras partes masculina y femenina."

Esta discusión entre Varela y Puente/Noble no generó debate en el correo de lectores, apenas un hombre salió a desmentir la sentencia de Silvia Puente acerca de que no había varones desnudos en el Arte como si un desnudo masculino fuese suficiente argumento para desacreditar el hecho de que el cuerpo femenino haya sido predominantemente tratado en las artes desde la perspectiva masculina del deseo, hecho que el crítico de arte John Berger había señalado en su libro Modos de ver en 1972. El mismo lector también expresaba su desacuerdo con la idea de que había algo novedoso en el trabajo de las mujeres fuera de sus casas, desde los "albores de la humanidad tanto mujeres como varones han debido dedicar sus esfuerzos a la difícil y esencial tarea de sobrevivir" (TAMBIÉN..., 1981, p. 23). Se trataba de una carta extensa que solo se detenía en esos dos puntos de la argumentación de la periodista.

Nos explayamos en el análisis de estas notas publicadas en HUM® no sólo para contextualizar la aparición de Marta Vicente en HUM®, sino también para dejar en evidencia que la desigualdad de género era argumentada en un medio masivo de comunicación aunque fueran discusiones con poca repercusión mediática. Entonces, no es que estos temas no se trataban, sino que no había 
capacidad de escucha que permitiese generar algún tipo de cambio o impugnación.

Figura 10 - Liberación

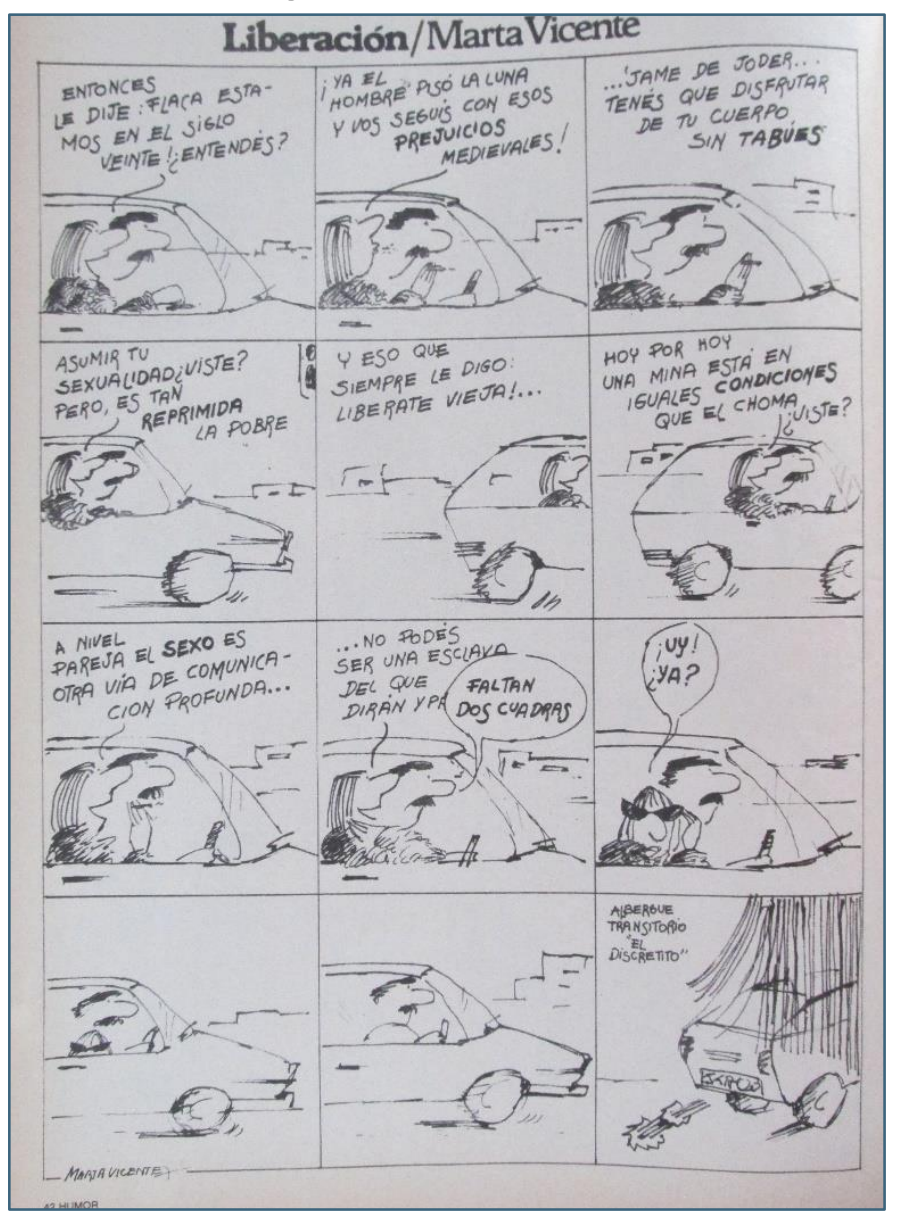

Fuente: VICENTE, 1981c, p. 40

Marta Vicente reemplazó a Claire Bretécher con producciones propias que estaban muy influenciadas temática, estilística y humorísticamente en la francesa aunque también por Sempé, otro humorista francés y por el estadounidense Jules Feiffer, ambos célebres desde fines de los años sesenta. De ellos, Vicente tomó el trazo sencillo, suelto, despojado (con escenografías mínimas) y expresivo. El potencial de la comicidad estaba en los diálogos más que en el dibujo, pero en este último Vicente logró la apariencia de espontaneidad propia de Bretécher. La nota distintiva de Vicente fue el uso de un lenguaje más coloquial y porteño en los diálogos (desde 1977 vivía con su familia en Buenos Aires) y no abstraerse de la crisis económica y política que vivía el país ni de la creciente politización que tuvo $H U M \otimes$. Así fue que pasó de abordar la liberación 
femenina y sus limitaciones - (FIGURA 10)- a tratar la retirada de los militares del poder. También visualmente, escapó a las representaciones de los cuerpos femeninos en clave de femme fatale o pin-up y siguió la línea de Bretécher: figuras humanas con cuerpos imperfectos según el canon de belleza dominantes. Si bien el cuerpo femenino fue representado de múltiples modos en HUM®, varios destacados dibujantes de la revista como por ejemplo Alfredo Grondona White y Horacio Altuna apelaban al modelo que respondía a la perspectiva masculina del deseo: la representación de la mujer como pin-up. Este modelo se había convertido en hegemónico dentro de la cultura de masas de Occidente y la Argentina no fue una excepción ${ }^{17}$.

En cuanto a los temas del humor, Marta Vicente comenzó burlándose de situaciones que para ella eran cotidianas y ya no eran varones burlándose de las mujeres sino mujeres burlándose de sí mismas, lo cual constituía una novedad para el humor costumbrista de tan larga tradición. Se reía de la pose intelectual y en la doble moral de las mujeres de clase media, de las mujeres que se creían sexualmente liberadas pero en los hechos no lo eran, de los desencuentros afectivos y sexuales de las parejas, del sentido común de clase media que circulaba y se reproducía en las charlas de mujeres, en las plazas y almacenes. Los protagonistas de sus tiras eran mujeres jóvenes o maduras, de clase media; la mayoría, amas de casa que comentaban los precios de los productos, lo que veían en televisión o leían en las revistas. Por ejemplo, una tira ridiculizó y expuso el anacronismo de la monarquía británica con motivo del casamiento de Diana Spencer y Carlos de Gales, que en la Argentina tuvo una gran cobertura mediática. En la tira de Vicente, dos mujeres de barrio comentaban las restricciones a las que debía someterse la nueva princesa y una concluía que "iEsta muchacha termina como JEFA del movimiento de liberación femenina!" (VICENTE; 1981b, p. 53).

\footnotetext{
7 En el caso del humor gráfico, las pin up se hicieron célebres gracias a Guillermo Divito, que llenó su revista Rico Tipo con "sus" chicas jóvenes, atractivas y sensuales a mediados de los años cuarenta y treinta años más tarde, todavía había dibujantes varones que seguían difundiendo esos imaginarios eróticos en los medios masivos de comunicación.
} 
Al principio de modo intercalado y sobre el fin de 1981 y comienzos de 1982 de forma regular, Marta Vicente comenzó a abordar la situación política y social del país en sus tiras. Mencionó el programa económico de la dictadura militar, aludió al aumento del costo de vida, a las cesantías y al creciente desempleo pero también al militarismo y el golpismo arraigado en la cultura política argentina, y a la imagen distorsionada de la realidad que transmitían los noticieros de la televisión. Después de la crisis política que terminó con el golpe palaciego que desplazó a Viola y nombró al general Leopoldo F. Galtieri como su sucesor; Marta Vicente publicó "Mariadita". Los personajes de la tira eran una pareja de clase media y mientras el hombre leía el diario, la mujer señalaba que estaban girados hacia la izquierda en la viñeta. Ella creía que su ubicación incorrecta se debía a que "la chica que hace la historieta está mariadita"; en cambio, el hombre sostenía que era una "Pobre mujer/iiNo quiere aceptar que el país se va a pique!!" (VICENTE, 1982a, p. 114) (FIGURA 11).

Figura 11 - Mariadita

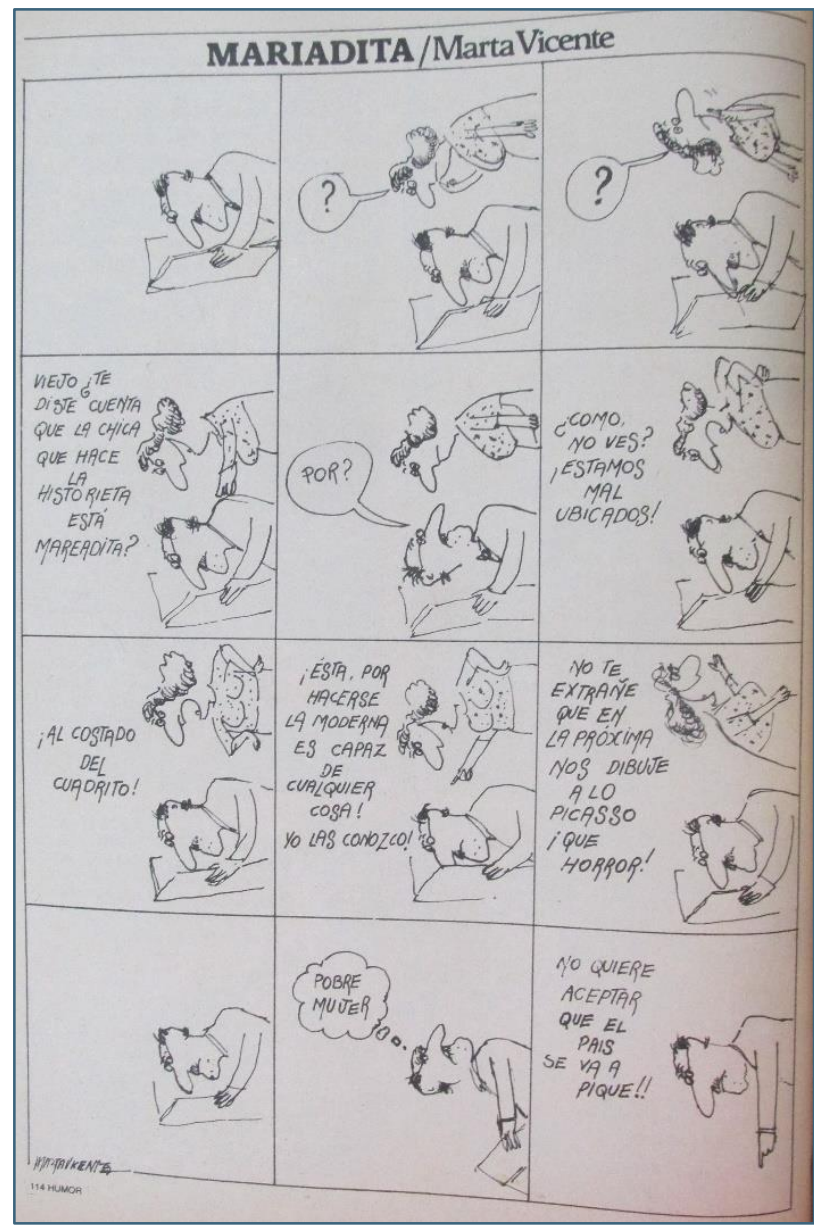

Fuente: VICENTE, 1982a, p. 114 
Después de esta entrega, Marta Vicente espació sus colaboraciones y la última de esta etapa en HUM® salió cuando la sociedad argentina aún no se había recuperado de la derrota en la guerra de Malvinas. En ella, un niño que jugaba a los soldaditos le preguntaba a su abuela cuántos generales había en el país, la abuela respondía "doscientos" para cerrar el tema pero el niño hacía una cuenta y concluía “¡Faltan 193 presidentes militares para que empiecen los civiles!" (VICENTE, 1982b, p. 36). Como dijimos, Marta Vicente abandonó el humor gráfico en 1982, clausurándose esta línea de humor hecho por mujeres que además de abordar el "mundo femenino" se animaba a aludir a la política. Hubo que esperar al retorno democrático y a la aparición de revistas como SexHUM® y Fierro para que irrumpan nuevamente mujeres en el campo del humor gráfico argentino.

\section{Reflexiones finales}

En los años setenta, el humor gráfico argentino se renovó con una nueva generación de dibujantes que irrumpió y se consagró en las principales revistas del género y en los diarios nacionales. Todos ellos eran varones, reforzando la idea de que el humor era cuestión de hombres y que la profesión era un territorio masculino. Sin embargo, a diferencia de otras coyunturas, en esta ocasión no se invisibilizó el trabajo de las mujeres que produjeron y publicaron en esas mismas revistas: en este artículo analizamos tres casos, que incluyen a cuatro mujeres, que tienen en común haber sido experiencias breves, interrumpidas.

En dos de los tres casos que analizamos, la irrupción de nuevas autoras fue celebrada en público por los editores (también fue bienvenida Claire Bretécher en $H U M \otimes$ y en SuperHUM® ${ }^{18}$ ). Estas bienvenidas reconocían los nuevos espacios que varias mujeres estaban conquistando a la vez que implícitamente comenzaba a verse como una necesidad el hecho de que hubiera mujeres que hicieran reír. Sin embargo, estas bienvenidas no impidieron que se manifiesten hechos y dichos sexistas, machistas o misóginos tanto por parte de varones como de mujeres. Tampoco alcanzó para retener a las que se animaron a

\footnotetext{
${ }^{18}$ Véase BURKART, 2018.
} 
incursionar en el mundo del humor gráfico y de la historieta, salvo el caso de Patricia Breccia que hizo carrera en el campo de la historieta y volvió a incursionar en el humor más tarde. Queda en evidencia que el proceso de expansión en clave de igualdad de género no fue lineal ni unívoco. Asimismo no podemos dejar de mencionar que ninguna de las autoras se asumió como feminista, más bien se trató de mujeres que, con más o menor seguridad de sí mismas, se animaron a incursionar en ese mundo dominado por varones y ofrecer su punto de vista para generar risa.

También en dos de los tres casos había vínculos familiares y matrimoniales que facilitaron el acceso de estas mujeres a los espacios de publicación y de sociabilidad, aunque no su permanencia, ni evitaron la presencia de otros obstáculos. Breccia se crio en una familia de artistas; Capozzo y Vicente estaban casadas con hombres vinculados al humor gráfico y a la historieta, y a las publicaciones donde se iniciaron. Esos vínculos funcionaron como capital social suficiente para que no fueran percibidas por los colegas como outsiders o "recién llegadas" al campo ya que antes de publicar, participaban de las instancias de sociabilidad de este (BOURDIEU, 2005). Algo que no sucedió con Nelly Hoijman, a quien el hecho de no tener esos contactos dentro del humor gráfico y la historieta, le valieron la mirada denigratoria de sus colegas y su temprana y denigratoria expulsión.

En efecto, el caso de Nelly Hoijman fue el más injusto, por la publicidad que tuvo en el medio: después de haber decidido no seguir publicando en Mengano por estar en desacuerdo con un cambio inconsulto que le habían hecho los editores de la revista a su tira, estos avalaron frente a la Asociación de Dibujantes de la Argentina la acusación de fraude realizada por un dibujante que trabajó para ella. En el Año Internacional de la Mujer según la ONU, esta acción colectiva en su contra la silenció para siempre, e interrumpiendo una carrera que podría haber sido promisora. Hoijman había aportado temáticas relacionadas al universo femenino en medios de prensa en que predominaban voces y miradas masculinas. Aún con limitaciones y reproduciendo ciertos machismos, dejó esas primeras tiras donde es una mujer la que le ofrece a otras mujeres un ejemplo de autoconcientización y autopercepción así como también la posibilidad de 
reírse de sí mismas a partir de representar las relaciones de pareja o la imagen de sí.

Unos años más tarde, las experiencias editoriales dirigidas por Andrés Cascioli fueron más auspiciosas y consecuentes con la incorporación de mujeres. La revista $H U M \otimes$ fue la primera en ese entonces en intentar que haya al menos una mujer humorista por edición, pero lo hizo sin condenar ni censurar el machismo de sus colaboradores ni de sus lectores, tampoco prescindió de discursos machistas y sexistas ni de algunas de sus prácticas más arraigadas. Ni la revista ni sus colaboradoras mujeres quisieron filiarse con el feminismo, movimiento que no tenía una aceptación masiva ni siquiera entre sectores intelectuales de clase media como podían ser las periodistas de estos medios. El feminismo era visto como una reacción contra los varones y de ahí el distanciamiento y los prejuicios tanto de varones como de mujeres.

A mediados de 1979, cuando HUM® había cumplido un año y estaba en proceso de expansión se produjo la incorporación de las primeras mujeres como guionistas y dibujantes. No fueron las únicas, como vimos, también se sumaron otras mujeres al equipo de redacción. Patricia Breccia y Lucía Capozzo integraron la primera dupla autoral de mujeres. Como señalamos, no se trataba de dos outsiders del mundo de la historieta y el humor como sí lo era Hoijman. No obstante, debieron lidiar con el rechazo de los lectores y con el machismo internalizado y los micromachismos, es decir, comportamientos de dominación invisibles llevados a cabo, en este caso, por un grupo de varones, y que muchas mujeres, por desconocimiento, los toleran o no los perciben o lo hacen acríticamente, con lo que contribuyen a perpetuarlas. (BONINO MÉNDEZ, 1996). Entonces, más allá de ciertas condiciones sociales y editoriales favorables, no dejaron de operar las desigualdades en las relaciones de género.

Las dificultades de Lucía Capozzo para autoconcebirse como autora de historietas plena, con derecho a la escritura, dan cuenta de las complejas y dolorosas situaciones que se dan entre creatividad y relaciones íntimas (CHADWICK; DE COURTIVRON, 1994) y la internalización del patriarcado: 
Esto es así porque nuestra cultura patriarcal ha legitimado la creencia de que el masculino es el único género con derecho al poder autoafirmativo: ser varón supone tener el derecho a ser individuo pleno con todos sus derechos (y derecho a ejercerlos). La cultura androcéntrica niega ese derecho a las mujeres. (BONINO MENDEZ, 1996, p. 2)

El caso de Marta Vicente también es distinto. Su incorporación no fue anunciada, no hubo una reacción por parte de los lectores y ese bajo perfil se extendió al debate público que hubo en la revista en relación al machismo y feminismo. La crisis política de la dictadura militar parecería ocupar toda la agenda mediática y pública, restándole interés a esas otras cuestiones. El humor gráfico y el periodismo hecho por mujeres mostraba y hablaba de la desigualdad de género y de la violencia de género, pero pareciera que no había poder de escucha. Al mismo tiempo y paradójicamente, la situación política crítica se plasmaba en la obra misma de Vicente que, como vimos, no se circunscribió al abordaje de las relaciones de género sino que se politizó, rompiendo de modo innovador esa idea de que las artistas o, más específicamente, las humoristas mujeres deben abordar casi de modo exclusivo los definidos como "temas femeninos" y "de mujeres".

\section{Referências}

ACEVEDO, Mariela. Sexualidades gráficas: sexuación del lenguaje y expresiones de la diferencia sexual en la revista Fierro (1984-1992 y 2006-2015). 2019. Tesis (Doctorado en Ciencias Sociales), Facultad de Ciencias Sociales, Universidad de Buenos Aires, Buenos Aires, inédita, 2019.

ACEVEDO, Mariela. Autoras de fierro: una aproximación a las "minas" que dibujan en una revista de historietas de los años '80. Descentrada: Revista Interdisciplinaria de feminismos y género, La Plata, v. 1, n. 2, p. 2-22, sept. 2017.

BARRANCOS, DORA. Mujeres en la sociedad argentina: una historia de cinco siglos. Buenos Aires: Sudamericana, 2010.

BERGER, John. Modos de ver. Barcelona: Gilli, 2014.

BERGER, Peter. Risa redentora: la dimensión cómica de la experiencia humana. Barcelona: Kairós, 1999. 
BONINO MÉNDEZ, Luis. Micromachismos, la violencia invisible en la pareja. In: JORNADAS SOBRE VIOLENCIA DE GÉNERO DE LA DIRECCIÓN GENERAL VALENCIANA DE LA MUJER. Valencia, 1996.

BOURDIEU, Pierre. Las reglas del arte: génesis y estructura del campo literario. Barcelona: Anagrama, 2005.

BRAVO TEDIN, Miguel. Hortensia \& Córdoba. Córdoba: Ediciones del Molino, 2001.

BRECCIA, Patricia. [Entrevista cedida a] Mara Burkart, Ciudad Autónoma de Buenos Aires, 7 feb. 2020.

BRECCIA, Patricia. [Entrevista cedida a] La Duendes, 2012. Disponible en: http://laduendes.blogspot.com/2012/07/entrevista-patricia-brecciaprimera.html. Acceso: 4 jul. 2018.

BURKART, Mara. Claire Bretécher en la revista HUM® (1979-1984) (O cómo hacer para que el humor gráfico argentino deje de ser una cuestión de hombres). Ártemis: Revista de estudos de gênero, feminismo, sexualidades e multiculturalismo. Paraíba, v. 26, n. 1, p. 6-28, 2018.

BURKART, Mara. De Satiricón a HUM®: risa, cultura y política en los años setenta. Buenos Aires: Miño \& Dávila, 2017.

CAPOZZO, Lucía. [Entrevista cedida a] Mara Burkart, Ciudad Autónoma de Buenos Aires, 28 feb. 2020.

CAPOZZO, Lucy; BRECCIA, Patricia. Rita y los oficios. HUM®, Buenos Aires, p. 46, ago. 1979.

CHADWICK, Whitney; DE COURTIVRON, Isabelle (ed). Los otros importantes: creatividad y relaciones íntimas. Madrid: Cátedra, 1994.

CILENTO. [Charge]. HUM®, Buenos Aires, n. 54, p. 14, mar. 1981.

DI PALMA, Roberto. [Entrevista cedida a] Mara Burkart, Córdoba, 1o jul. 2010.

EL PAVOROSO retorno de Cristina. HUM®, Buenos Aires, n. 18, p. 13, ago. 1979.

FACIO, Ada; FRIES, Lorena. Feminismo, género y patriarcado: lecturas de apoyo. Academia, Revista sobre enseñanza del Derecho, Buenos Aires, Año 3, n. 6, p. 23-45, primavera 2005. 
GIUNTA, Andrea. Feminismo y arte latinoamericano: historia de artistas que emanciparon el cuerpo. Buenos Aires: Siglo XXI, 2018.

GRAY, Frances. Women and laughter. London: Macmillan, 1994.

GREMIALES. El Tablero, Buenos Aires, n. 5, p. 4, mar. 1975.

HOIJMAN, Nelly. [Entrevista cedida a] Mara Burkart, Ciudad Autónoma de Buenos Aires, 21 dic. 2019.

HOIJMAN, Nelly. [Entrevista cedida a] Mara Burkart, Ciudad Autónoma de Buenos Aires, 12 may. 2018.

HOIJMAN, Nelly. ¿Qué buscan los hombres en las mujeres? Damas y Damitas, Buenos Aires, n.7, p. 17-18, jun. 1975d.

HOIJMAN, Nelly. Donna. Siete Días, Buenos Aires, n. 409, 10 abr. 1975c.

HOIJMAN, Nelly. Donna. Siete Días, Buenos Aires, n. 405, 13 mar. 1975b

HOIJMAN, Nelly. Donna. Siete Días, Buenos Aires, n. 402, 20 feb. 1975a.

HOIJMAN, Nelly. El humor tiene cara de mujer. Mengano, Buenos Aires, n. 5, p. 8, oct. 1974 a.

HOIJMAN, Nelly. Mengano, Buenos Aires, n. 6, p. 14, oct. 1974 b.

ITKIN, Silvia. Mujeres humoristas: hacia una sonrisa sin sexismo. Feminaria, Buenos Aires, n. 2, p. 22-26, nov. 1988.

JUSZKO, Paulina. El humor de las argentinas. Buenos Aires: Editorial Biblos, 2000.

KERGOAT, Danièle. Divisão sexual do trabalho e relações sociais de sexo. In: HIRATA, H. et al. (org.). Dicionário crítico do feminismo. São Paulo: Editora UNESP, 2009. p. 67-75.

LA INTOLERANCIA. HUM®, Buenos Aires, n. 54, p. 5, mar.1981.

LEGA, Leonor; VELTEN, Emmett. Albert Ellis (1913-2007). Revista

Latinoamericana de Psicología, Bogotá, v. 40, n.1, p. 189-193, enero/abr. 2008.

MAICAS, Eduardo; BUTTAFUOCO. Comedia de(s)parejas. HUM®, Buenos Aires, n. 54, p. 34, mar. 1981. 
MALOSETTI COSTA, Laura. Introducción. In: POLLOCK, Griselda. Visión y diferencia: feminismo, feminidad e historias del arte. Buenos Aires: Fiordo, 2013. p. 11-18.

MASIELLO, Francine. Entre civilización y barbarie: mujeres, nación y cultura literaria en la Argentina moderna. Rosario: Beatriz Viterbo editora, 2007.

MASIELLO, Francine. La mujer y el espacio público. El periodismo femenino en la Argentina del siglo XIX. Buenos Aires: Feminaria editora, 1994.

MENGANOSCOPIO. Mengano, Buenos Aires, n. 6, p. 3, oct. 1974.

NACIÓ una estrella: se llama Rita. ¡Socorro! HUM®, Buenos Aires, n. 17, p. 52, jul. 1979.

NOCHLIN, Linda. ¿Por qué no han existido grandes artistas mujeres? In: CORDERO REIMAN, Karen; SÁENZ, Inda (comps.). Crítica feminista en la teoría e historia del arte. Ciudad de México: Curare, 2001. p. 17-43.

POLLOCK, Griselda. Visión y diferencia: feminismo, feminidad e historias del arte. Buenos Aires: Fiordo, 2013.

POLLOCK, Griselda. Diferenciando: el encuentro del feminismo con el canon. In: Cordero Reiman, Karen; Sáenz, Inda (comps.). Crítica feminista en la teoría e historia del arte. Ciudad de México: Curare, 2001. p. 141-158.

PUENTE, Silvina; NOBLE, Cristina. Dos mujeres contra todos. HUM®, Buenos Aires, n.56, p. 53-55, abr. 1981.

RAFAEL. [Tira cómica]. Satiricón, Buenos Aires, n. 12, p. 48, oct. 1973.

RUSSO, Sandra. Memorias de una joven formal. HUM®, Buenos Aires, n. 55, p. 6 7, mar. 1981.

SADOMASOQUISTA perseguidor. HUM®, Buenos Aires, n. 19, p. 12-13, sept. 1979.

SCARZANELLA, Eugenia. Abril: un editor italiano en Buenos Aires, de Perón a Videla. Buenos Aires: Fondo de Cultura Económica, 2016.

TAMBIÉN hay varones desnudos. HUM®, Buenos Aires, n. 58, p. 23-24, may. 1981.

VARELA, Santiago. Elogio y defensa del machismo. HUM®, Buenos Aires, n. 54, p. 35-36, mar. 1981. 
VASSALLO, Alejandra. "Las mujeres dicen basta”: movilización, política y orígenes del feminismo argentino en los 70. In: ANDÚJAR, Andrea; DOMíNGUEZ, Nora; RODRÍGUEZ, María Inés. Historia, género y política en los '70. Buenos Aires: Feminaria, 2005. p. 61-88.

VAZQUEZ LUCIO, Oscar (Siulnas). Historia del humor gráfico y escrito en la Argentina. Buenos Aires: Eudeba, 1986.

VELÁZQUEZ, Susana. Violencias cotidianas, violencia de género: escuchar, comprender, ayudar. Buenos Aires: Paidós, 2003.

VICENTE, Marta. [Entrevista cedida a] Mara Burkart, Ciudad Autónoma de Buenos Aires, 6 abr. 2017.

VICENTE, Marta. Humor femenino. HUM®, Buenos Aires, n. 54, p. 48, mar. 1981a.

VICENTE, Marta. Pobrecita Lady. HUM®, Buenos Aires, n. 65, p. 53, sept. 1981b.

VICENTE, Marta. Liberación. HUM®, Buenos Aires, n. 63, jul. 1981c.

VICENTE, Marta. Mariadita. HUM®, Buenos Aires, n. 76, p. 114, febr. $1982 a$.

VICENTE, Marta. Cuantos. HUM®, Buenos Aires, n. 86, p. 36, jul. 1982b.

Universidade do Estado de Santa Catarina - UDESC

Programa de Pós-Graduação em História - PPGH

Revista Tempo e Argumento Volume 12 - Número 31 - Ano 2020 tempoeargumento@gmail.com 